REVESCO. Revista de Estudios Cooperativos

ISSN: $1885-8031$

https://dx.doi.org/10.5209/REVE.75567

\title{
¿Son transparentes las empresas que reciben subvenciones? El impacto social en España y su evaluación
}

\author{
Luis Martínez Laguna ${ }^{1}$, Elena Urquía Grande ${ }^{2}{ }^{-}$y Ricardo Palomo Zurdo ${ }^{3}[$
}

Recibido: 9 de marzo de 2021 / Aceptado: 15 de abril de 2021 / Publicado: 22 de junio de 2021

Resumen. Este trabajo aborda como objetivo principal la propuesta de un modelo, al que denominaremos "Transparencia de las Empresas que reciben Subvenciones" (TESUB), que posteriormente se aplicará para valorar cómo se está realizando la comunicación de la información en estas entidades privadas cuando el órgano concedente sea una administración pública. Se ha configurado una propuesta previa de indicadores, que se han contrastado con los indicadores del sistema español de acreditación de la transparencia, para configurar un modelo que también posibilite una certificación en transparencia. Se pueden agrupar en tres áreas de transparencia, la relacionada con información obligatoria a publicar en base al nuevo contexto de la ley de transparencia, la conectada con información publicada, en el contexto de los principios de transparencia y prevención de la corrupción para las empresas (Transparencia Internacional-España) y la ligada con información voluntaria publicada, que desarrolla principalmente las tres dimensiones de la responsabilidad social corporativa. La Metodología de Evaluación y Seguimiento de la Transparencia de la Actividad pública (MESTA) se ha tomado como un modelo de referencia para diseñar TESUB, como modelo propio para las entidades privadas, para dotarle de mayor potencia metodológica y contar con un instrumento de medición tanto cuantitativo como cualitativo, con valoraciones que atiendan a la calidad de la información suministrada y al soporte web. TESUB posibilita la valoración de la transparencia en sentido amplio, ya que calcula tres índices de evaluación que aportan mediciones específicas en cada bloque, que a su vez se pueden ir agregando, pero también los datos por componentes de la publicidad activa nos permitirán identificar áreas de mejora.

Palabras clave: Índices de revelación; Rendición de cuentas; Publicidad activa; Prevención de corrupción; Sostenibilidad social; Acreditación en Transparencia.

Claves Econlit: K49; L29; M14; O35.

[en] Are companies receiving grants transparent? The social impact in Spain and its evaluation

Abstract. The main objective of this paper is the proposal of a model framework, named as "Business Transparency of
Enterprises that receive Grants" (TESUB), which will, afterwards, be applied to evaluate how these private enterprises
communicate and share information when the transferor of such information is a public administration body. A prior
proposal of indicators has been designed, those indicators have been contrasted with the ones present in the Spanish
system of transparency accreditation, to develop a model that makes possible the certification of transparency. The
model presents three groups of transparency, the one related with mandatory reporting of information due to the new
transparency laws, the one related with their actual published information (regarding the principles of transparency and
stoppage of money laundering. International Transparency-Spain) and the one linked with voluntary reported
information (that follows the three dimensions of Corporate Social Responsibility). The methodology for evaluation and
monitoring of the Public Activity Transparency has been used as a reference model to create TESUB, as it is a model
targeted to private companies, with the intention to provide to our model framework with more methodological strength
and to have an additional instrument of both quantitative and qualitative measurement, with a valuation that reside on
the quality of the supplied information and the website. TESUB makes possible to value the concept of transparency as
a whole since it works with three main evaluation indicators which provide specific measurement of each, that at the
same time can be added, and in addition it segregates the data by components of the active advertising which will assent
to the identification of improvement areas.

Keywords: Disclousure rate index; Accountability; Active Advertisement; Anti-Corruption Policies; Social Sustainability; Transparency accreditation.

1 Universidad San Pablo CEU de Madrid, España (investigador en formación de CEU-CEINDO, en el programa de doctorado en Derecho y Economía).

Dirección de correo electrónico: marlag@ceu.es.

2 Universidad Complutense de Madrid, España.

Dirección de correo electrónico: eurquiag@ ccee.ucm.es

3 Universidad San Pablo CEU de Madrid, España.

Dirección de correo electrónico: palzur@ceu.es. 
Sumario. 1. Introducción. 2. El estado de la cuestión. Nuevo marco legal y transparencia 3. Diseño del modelo TESUB y acreditación en transparencia. 4. La metodología MESTA como referente de TESUB. 5. Diseño y aplicabilidad de TESUB. 6. Conclusiones. 7. Referencias bibliográficas.

Cómo citar. Martínez Laguna, L.; Urquía Grande, E.; Palomo Zurdo, R. (2021) ¿Son transparentes las empresas que reciben subvenciones? El impacto social en España y su evaluación. REVESCO. Revista de Estudios Cooperativos, vol. 138 , e75567. https://dx.doi.org/10.5209/reve.75567.

\section{Introducción}

Este trabajo aborda como objetivo principal la propuesta de un modelo, al que denominaremos Transparencia de las Empresas que reciben Subvenciones (TESUB).

Los resultados de la aplicación del modelo permitirán medir y evaluar el grado de cumplimiento de las empresas que reciben subvenciones en la divulgación de información, dentro de las diferentes áreas de transparencia donde se agrupan los indicadores propuestos.

Como objetivo secundario se plantea contrastar y validar el modelo TESUB con un sistema de evaluación considerado referente, que puede aplicarse a instituciones privadas, el sistema español de acreditación de la transparencia.

La organización internacional conocida bajo la denominación de Transparencia Internacional (TI) elaboró y publicó los "Principios de Transparencia y Prevención de la Corrupción para las empresas" con la finalidad de establecer patrones de actuación que ayuden a las compañías a desarrollar sus actividades con transparencia y responsabilidad social.

El número 6. Información pública de las contrataciones con el sector público e información de las actividades subvencionadas con ayudas públicas va en línea con la obtención de lograr un sistema de transparencia e información para la prevención de la corrupción en las administraciones públicas, pero también en la consecución de valor en la actividad empresarial. La publicidad se puede dar por ejemplo a través de la página web corporativa.

Este principio supone un claro antecedente de la legislación actual en la transparencia de las empresas que reciben subvenciones, que pasamos a relatar.

España ha adoptado una nueva regulación de la transparencia y el derecho de acceso a la información pública, equiparándose a la Unión Europea y a la mayoría de sus Estados miembros. Se trata de la Ley 19/2013, de 9 de diciembre, de transparencia, acceso a la información pública y buen gobierno (en adelante LTBG) que es una ley de mínimos cuyas medidas pueden reforzarse por leyes autonómicas de transparencia, y que tiene pendiente de publicación el correspondiente reglamento de desarrollo.

La LTBG avanza y profundiza en la configuración de obligaciones de publicidad activa que vinculan a todas las administraciones públicas, pero también a determinadas entidades por su condición de perceptores de fondos públicos, e igualmente a entidades privadas obligadas a suministrar información por petición de las administraciones públicas.

Resulta una novedad las recomendaciones y obligaciones de transparencia de la actividad pública en relación con los siguientes actos de gestión administrativa:

- Subvenciones y ayudas públicas concedidas con indicación de su importe, objetivo o finalidad y beneficiarios.

Desde este punto de partida se ha identificado:

- En primer lugar, la necesidad de diseñar un modelo que permita posteriormente valorar la transparencia en las entidades privadas que reciben subvenciones, cuando el órgano concedente sea una administración pública.

- En una segunda fase se aplicará el modelo a una muestra amplia de empresas grandes, con el objetivo de elaborar un índice de información o transparencia, basado a su vez en un conjunto de índices, utilizando la técnica del análisis de contenidos de las páginas web. Finalmente, se presentarán los resultados por empresas, por áreas de transparencia y se analizará la influencia de algunas variables externas al cálculo de índices de transparencia.

En cuanto a la metodología aplicada se plantea primeramente un método analítico y exploratorio del nuevo marco legal, básicamente de la ley de transparencia y de la última versión de su reglamento de desarrollo, todavía pendiente de aprobación y de la literatura previa sobre transparencia y su medición.

A partir de este razonamiento se ha configurado una propuesta de indicadores que se pueden agrupar en tres bloques o áreas de transparencia que se conectan con tres de los aspectos o las definiciones de lo que es la transparencia empresarial. Se contrastan con los indicadores del sistema español de acreditación de la transparencia en las áreas de publicidad activa y organización transparente, que son las aplicables a entidades privadas de mercado. 
A continuación, se diseña el modelo tomando como referente la Metodología de Evaluación y Seguimiento de la Transparencia de la Actividad pública denominado MESTA, finalizándose con un apartado de conclusiones, que sintetiza nuestras aportaciones.

\section{El estado de la cuestión. Nuevo marco legal y transparencia}

La Ley 19/2013, de 9 de diciembre, de transparencia, acceso a la información pública y buen gobierno vino a regular la transparencia y el acceso a la información en el ámbito público y privado español, que se ha considerado una materia históricamente no atendida.

Incorpora una serie de preceptos que tienen consecuencias en el sector empresarial privado. Un tipo de obligación es la relacionada con la publicidad activa de información, siendo su entrada en vigor el 10 de diciembre de 2014.

Está pendiente de aprobación el borrador de Real Decreto por el que se aprueba el reglamento de desarrollo de la ley de transparencia, que se estructura en 4 capítulos y consta de 40 artículos y cinco disposiciones adicionales. Pretende facilitar el cumplimiento de las obligaciones de publicidad activa y favorecer el ejercicio del derecho de acceso por la ciudadanía, siendo uno de sus objetivos completar el marco normativo existente en materia de transparencia en España.

En primer lugar, se identifican las entidades privadas obligadas, se mencionan los diferentes tipos de datos y su publicación a realizar, y se consideran los principios generales para cumplir con estas disposiciones. A continuación, se enmarca la transparencia y su medición en el ámbito organizacional tanto público como privado.

\subsection{Entidades privadas obligadas en materia de publicidad activa}

El capítulo II de la LTBG, dedicado a la publicidad activa, establece una serie de obligaciones para los sujetos incluidos en el ámbito de aplicación del título I de la Ley, que regula la transparencia de la actividad pública, siendo muy amplio el ámbito subjetivo de aplicación. En este sentido, el artículo 3 de la LTBG especifica que las disposiciones de este capítulo II también serán aplicables a determinadas entidades que, por su condición de perceptores de fondos públicos, vendrán obligados a reforzar la transparencia de su actividad.

En concreto, se aplicará a todas las entidades privadas que perciban una determinada cantidad de ayudas o subvenciones públicas. Se consideran sujetos obligados por la norma:

- Las que perciban una cantidad superior a 100.000 euros en ayudas o subvenciones de carácter público, durante el periodo de un año.

Aquellas en las que al menos el $40 \%$ del total de sus ingresos anuales tengan carácter de ayuda o subvención pública durante el periodo de un año, siempre que alcancen la cantidad mínima de 5.000 euros.

\subsection{La información relativa a la publicidad activa y sus principios generales}

La información que debe publicarse por las entidades privadas que reciban una determinada cantidad de subvenciones o ayudas públicas, en sus páginas web institucionales, hace referencia a:

- Información institucional, organizativa y de planificación (artículo 6 LTBG).

- Información de naturaleza económica, presupuestaria y estadística (artículo 8 LTBG).

Se considera relevante para garantizar la transparencia de la actividad realizada por entidades privadas y está relacionada con el funcionamiento y control de la actuación pública.

La Metodología de Evaluación y Seguimiento de la Transparencia de la Actividad pública denominado MESTA (Aritmendi, 2017) se diseñó a partir de un convenio entre el Consejo de Transparencia y Buen Gobierno (CTBG) y la Agencia Estatal de Evaluación de las Políticas Públicas y la Calidad de los Servicios (AEVAL), cuyas funciones las ha asumido la Secretaría de Estado de Función Pública, tras su disolución por el Real Decreto 769/2017, de 28 de julio. Se considera la primera metodología oficial para aplicar a los sujetos obligados por la LTBG. Resulta destacable la consulta y referencia al Anexo I ${ }^{4}$. Definiciones de las obligaciones en materia de publicidad activa, correspondientes a MESTA, que como su propio nombre evidencia contiene una serie de definiciones del contenido de las informaciones obligatorias de transparencia en publicidad activa, que se realizan exclusivamente a efectos de su aplicación en la metodología, sin que se puedan considerar un desarrollo de la ley de transparencia, y siempre a la espera de la publicación de su

4 El informe MESTA y sus Anexos (30/06/2016) están disponibles en:

https://www.consejodetransparencia.es/ct Home/Actividad/documentacion.html. 
reglamento de desarrollo. Resultan interesantes puesto que incluyen alusiones específicas a las entidades privadas, donde se encuentran las empresas.

Por su parte, el artículo 5 LTBG establece que la información sujeta a las obligaciones de transparencia será publicada en las correspondientes sedes electrónicas o páginas web, siguiendo unos principios generales.

La finalidad es que resulte comprensible y accesible para los ciudadanos, ya que se considera por la ley un instrumento que tiene que optimizar el control de la gestión y utilización de los recursos públicos. Siguiendo a Amoedo (2016:9) "El ideal que procura la norma apunta a que la información no solo se publique en la forma antes indicada, sino que además se divulgue y se explique".

En definitiva, la información será publicada:

- $\quad$ De forma periódica y actualizada.

- $\quad$ De una manera clara, estructurada y entendible para los interesados.

- $\quad$ Preferiblemente, en formatos reutilizables.

- Toda la información será comprensible, de acceso fácil y gratuito y a disposición de las personas con discapacidad.

Las empresas grandes tienen que cumplir con todas las obligaciones de publicidad activa, explicitadas en la ley de transparencia, utilizando su página web corporativa como canal de información. Se sigue la Recomendación 2003/361/CE de la Comisión, de 6 de mayo de 2003 sobre la definición de microempresas, pequeñas y medianas empresas. No obstante, el borrador de reglamento amplía la posibilidad de utilizar los medios electrónicos de las organizaciones representativas o sectoriales a las que pudieran pertenecer cualesquiera de las empresas, para efectuar la divulgación.

\subsection{La transparencia y su medición}

La organización internacional conocida bajo la denominación de Transparencia Internacional (TI), dentro de su guía de lenguaje claro sobre lucha contra la corrupción, define la transparencia como la cualidad de un gobierno, empresa, organización o persona de ser abierta en la divulgación de información, normas, planes, procesos y acciones.

El objetivo fundamental de TI es la lucha contra la corrupción, adoptando la transparencia como un incentivo de las buenas prácticas en la gestión de las entidades. La falta de transparencia ha sido y es la consecuencia y la causa de la corrupción en las organizaciones, siendo uno de los indeseables efectos de la corrupción para los ciudadanos la vulneración de derechos, consecuencia de instituciones poco transparentes. La gestión de los servicios públicos es promovida por el derecho de los ciudadanos a recibir información pública (Etzioni, 2014). Un estudio sobre el Índice de Percepción de la Corrupción (IPC), de Transparencia Internacional (2017), que clasificó a 180 países y territorios por sus niveles de corrupción percibida en el sector público, según expertos y empresarios, evidenció que la reducción de la corrupción tiene un impacto significativo en el desarrollo económico y la inversión. Del Campo, Hermosa del Vasto, Urquía y Jorge (2020) destacan un marco de interrelaciones entre gobernabilidad, corrupción e indicadores de desarrollo socioeconómico. Bastida y Benito (2006) demuestran que la transparencia presupuestaria está correlacionada negativamente con la corrupción y positivamente con el desarrollo económico y en esta línea Filgueiras (2016) aduce que desarrollo económico y transparencia van al unísono.

Armstrong (2005) define la transparencia como "acceso ilimitado del público a información oportuna y confiable sobre decisiones y desempeño en el sector público". La transparencia de una entidad gubernamental viene determinada por su mayor disponibilidad de información y su apertura en la toma de decisiones (Armstrong, 2011).

La transparencia en el entorno organizacional significa que la empresa tiene la disposición de informar sobre su situación actual, de qué decisiones se toman y por quiénes son tomadas (Alonso, 2009). En esta línea, se puede definir la transparencia organizacional como facilidad que da la organización para acceder a la información acumulada sobre sí misma y al conocimiento construido por la misma organización (Ayestarán, 2016).

La rendición de cuentas o accountability es entendida como una parte de la transparencia, y supone la presentación de informes públicos referentes a impactos, procesos, estructuras de gobierno, fuentes de financiación (Andrade y Yaskelly 2007) y flujo de recursos (Plá, 1997). Hermosa del Vasto, del Campo, Urquía y Jorge (2019) presentan una revisión sobre la rendición de cuentas y sus implicaciones, exponiendo la definición generalmente aceptada utilizada por Lourenco (2015) basada en las proporcionadas por Armstrong (2005) y Bovens (2007), para quienes la rendición de cuentas pública se entiende como la obligación de los funcionarios públicos de informar sobre el uso de recursos y responsabilidad de la Administración ante el público para cumplir con los objetivos de desempeño establecidos. Implica que los actores que rinden cuentas tienen la obligación de actuar de manera consistente con los patrones de 
comportamiento aceptados de comportamiento ético y que serán sancionados por no hacerlo (Grant y Keohane, 2005).

Es ante todo un acto de responsabilidad, en donde la entidad evalúa, comunica sus logros, sus fallos y sus planes de mejora, influyendo en la percepción que se tiene sobre su competitividad, innovación y productividad (Medina, Lavin, Mora y de la Garza, 2011; Bravo, Matute y Pina, 2011).

Aunque los mayores retos están en las instituciones públicas, Transparencia Internacional (2020) realiza un llamamiento a las empresas privadas para adoptar y compartir el compromiso con su objetivo estratégico de promover y exigir una rendición de cuentas desde todos los niveles.

En el estudio de divulgación de información por parte de las empresas, uno de los instrumentos más empleados para evaluar la transparencia es la determinación de los índices de revelación, como indicador numérico representativo de la cantidad y calidad de la información expuesta en el canal de comunicación objeto de estudio (García y Martínez, 2004).

Si efectuamos una revisión histórica inicial de la literatura, los trabajos más destacados se relacionan con el empleo de índices ponderados o no ponderados, la fuente de obtención de información, la elección de las variables que componen el contenido y seguidamente la elección de unas u otras variables explicativas de los índices de transparencia (Ortiz y Clavel, 2006).

La transparencia debería ayudar usuarios para determinar la capacidad de una entidad o gobierno para cumplir con sus compromisos de sostenibilidad (Guthrie, Ball y Farneti, 2010; Meijer, 2013; Piotrowski, 2009).

Uno de los problemas actuales de las mediciones de la transparencia, en el contexto de los sistemas de medición del grado de transparencia de las entidades públicas, son problemas de tipo metodológico. Los principales instrumentos de medición fueron en su inicio una palanca esencial para el impulso a la transparencia, si bien hoy en día se acusa su falta de adaptación a los avances que se están produciendo y el que no exista un estándar al respecto, donde cada entidad que realiza las mediciones aplica los criterios que estima conveniente (Sierra, 2018).

Ros (2018) realiza un análisis de los índices desarrollados por Transparencia Internacional España (TIE) y MESTA, poniendo de manifiesto algunas limitaciones y cómo corregirlas.

A partir de la publicación de la LTBG se han diseñado metodologías dispares por entidades de diversa naturaleza, tanto públicas como privadas, aunque prácticamente todas siguen un mecanismo similar que comprueba el cumplimiento de unos indicadores cuyo número varía significativamente.

No obstante, la elección de los indicadores sigue siendo uno de los pilares en los que se asienta la construcción de índices de transparencia, pero no el único. Para Marcuello, Bellostas y Moneva (2007) la transparencia se entiende como la actitud y la disponibilidad de informar. Debido a ello, la transparencia implica algo más allá de la rendición de cuentas; también requiere la garantía de acceso, apertura y visibilidad de la información que permita la certidumbre, la estabilidad y la gobernabilidad que la sociedad necesita para su conservación y desarrollo (Uvalle, 2007).

\section{Diseño del modelo TESUB y acreditación en transparencia}

Para valorar la información divulgada a través de sus páginas web por las distintas empresas que son receptoras de subvenciones, cuando el órgano concedente sea una administración pública, se tiene la intención de elaborar un índice de información o transparencia, específico para el contexto de estas entidades privadas.

El procedimiento de evaluación del nivel de transparencia se basará en un conjunto de indicadores de evaluación, que se agruparán en una serie de bloques o áreas de transparencia, que hacen referencia tanto a contenidos como a principios relacionados con la forma de realizar la publicación.

La publicación de indicadores de desempeño y la divulgación de información financiera y no financiera en un formato comprensible (Bauhr \& Grimes, 2014) que permite un seguimiento continuado y realizar comparaciones relevantes a lo largo del tiempo (Heinrich, 2002; Bushman y Smith, 2003; Propper y Wilson, 2003) se considera una de las mejores prácticas sobre transparencia para la rendición de cuentas en las administraciones públicas. Se puede hacer extensiva esta línea de pensamiento a las entidades privadas, para que sus grupos de interés puedan igualmente contar con una herramienta que les permita el control de gestión de las subvenciones recibidas y los resultados obtenidos.

Se aborda la propuesta de un modelo específico en las empresas que reciben subvenciones, al que denominaremos Transparencia de las Empresas que reciben Subvenciones (TESUB), donde se han determinado tres bloques o áreas de transparencia:

1. Relacionada con información obligatoria a publicar, en base a la ley de transparencia. La normatividad resulta fundamental en el proceso de transparencia, pues permite definir la precisión y la documentación de los procesos que han de estar a cargo de cada uno de los actores que intervienen en la toma de decisiones, mejorando con ello la información y la relación entre los actores y la 
organización. No obstante, la transparencia en información es un criterio o un conjunto de criterios de acción colectiva, no un valor universal o normativo, en un contexto de información costosa y racionalidad limitada, que deben ser incorporados por las organizaciones no solo normativamente, y sí organizativamente, con el fin de que cobre sentido en las mismas. Para que el éxito de una política de transparencia se dé, es imprescindible su incorporación a la cultura organizativa (en sus estructuras y en la toma de decisiones) y social (Arellano, 2007).

2. Conectada con información publicada, en el contexto de los principios de transparencia y prevención de la corrupción para las empresas (TI-España) completados con la referencia de los indicadores del sistema español de acreditación de la transparencia. Se entiende que la transparencia es la antítesis de la corrupción. La relación entre transparencia y corrupción es un problema que ha sido ampliamente estudiado en el ámbito público, de acuerdo con Argandoña (2003), pero pocas veces explorada en el ámbito privado por parte de la literatura, por tratarse de situaciones menos frecuentes. El entendimiento empresarial hace énfasis en la eficiencia y la productividad, a lo que se suma la influencia de un entorno empresarial globalizado, lo que reduce la propensión a incurrir en la falta de transparencia que refleja la corrupción que se puede presentar en las organizaciones.

3. Ligada con información voluntaria publicada, que desarrolla las dimensiones económica, social y medioambiental de la responsabilidad social corporativa y otras áreas afines de reporting corporativo. Se puede establecer un vínculo entre la Responsabilidad Social Empresarial (RSE) y la transparencia, ya que la responsabilidad derivada de la actividad empresarial comprende el cumplimiento estricto de las obligaciones legales (Carrol, 1979), pero también requiere gestionar aspectos que las leyes no pueden determinar en todos sus detalles e implicaciones, donde se integran las preocupaciones sociales, laborales, medioambientales y de respeto a los derechos humanos que surgen de la relación y el diálogo transparente con los grupos de interés (stakeholders) y que de esta forma la transparencia se vuelva efectiva. Entre estos aspectos se encuentran las condiciones que permiten el desarrollo personal en el trabajo, el respeto a los consumidores como clientes y como ciudadanos con derechos, la conciliación del trabajo y la vida personal de los empleados, el impacto de la actividad en el entorno social y natural, el cuidado del medio ambiente, la transparencia informativa con accionistas y acreedores, entre otros (Longinos, Arcas, Martínez y Olmedo, 2012: 89-90). Diversos estudios vinculan la transparencia con la que no es exclusiva a los inversores sino a todo aquel grupo de interés que se vea afectado directamente por las decisiones de las empresas, ya sean sociales, públicas o privadas (Ruiz, Tirado y Morales, 2008).

De forma complementaria, se han buscado las conexiones con los indicadores del sistema español de acreditación de la transparencia aplicables a entidades privadas de mercado, y de esta forma evitar dobles esfuerzos en la configuración de la información necesaria para poder realizar una acreditación en transparencia.

Los modelos para evaluar y certificar los procesos de transparencia se orientan a verificar que las entidades y sus grupos de interés respetan pautas en el ámbito laboral, ambiental y social, complementando adecuadamente su disposición a informar. El proceso de verificación implica que la transparencia sea parte de la forma de operar de la empresa, influyendo en la actividad y resultados financieros de la misma (Baraibar y Luna, 2012).

\section{1. Área de transparencia relacionada con información obligatoria a publicar, en base a la ley de transparencia}

Nuestra medición va a indagar en medir la transparencia de las empresas que reciben subvenciones, con unos mínimos de contenido que debemos incluir por corresponderse con la relación de información objeto de publicidad activa que establece la LTBG (arts. 6 a 8 ).

Por consiguiente, el contexto no es el mismo que para las entidades públicas, pero sí vamos a tomar en consideración los siguientes aspectos:

- El punto de partida de la información obligatoria a publicar, en base a todo lo regulado por la ley de transparencia.

Tomar como una comparativa válida un sistema de valoración considerado referente, que puede aplicarse a instituciones privadas, el sistema español de acreditación de la transparencia.

La propuesta de Indicadores de la ley de transparencia, que se desarrolla a continuación en la tabla 1, se enmarca en la primera área de transparencia de la primera fase del diseño del modelo TESUB, considerando los aspectos anteriormente citados. A continuación, se ha indagado en las posibles relaciones con un sistema considerado un referente, que sirva para canalizar la consecución de una acreditación en transparencia. 
En base a las disposiciones de la LTBG se justifica la selección de cada uno de los indicadores enumerados, que aparecen recogidos en la tabla 1, que se refieren a los contenidos de publicidad activa y se ajustan a los principios generales para que la publicación en las páginas web resulte efectiva.

Se hace constar que se han complementado los indicadores I 10 (Cuentas anuales individuales de la empresa) e I 12 (Informes de auditoría externa de las cuentas anuales) con un indicador adicional, I 12, no explicitado en la ley de transparencia, que sería el que hace referencia a la elaboración del informe de gestión, que también conllevaría, en su caso, su revisión por el auditor de cuentas.

No obstante, conviene remarcar una circunstancia en base a lo estipulado en el artículo 262.3 de la Ley de Sociedades de Capital (LSC): este indicador no sería aplicable a las pequeñas empresas, al tratarse de sociedades que formulan balance y estado de cambios en el patrimonio neto abreviados, no estando obligadas a elaborar el informe de gestión.

De forma complementaria, acudiendo a la regulación establecida en la tercera parte del Plan General de Contabilidad, dentro del apartado I, punto 4, de normas de elaboración de las cuentas anuales, se deduce que las sociedades cotizadas en un mercado miembro de la Unión Europea sí están obligadas a elaborar el informe de gestión, ya que se especifica que no podrán formular cuentas anuales abreviadas.

La referencia que aparece en el indicador I 16 se especifica en el reglamento de la ley de transparencia, en cuanto a que los ejercicios anteriores sean 4 años.

Se ha considerado un indicador adicional, el I 17, como consecuencia de aparecer recogido como principio general en el reglamento de la ley de transparencia.

Tabla. 1. Indicadores de publicidad activa de las empresas que reciben subvenciones.

\section{Información institucional, organizativa y de planificación (7)}

I 1. Actividades que desempeña la empresa según figura en su objeto social, ya sean las principales u otras accesorias.

(Posible identificación de las actividades con los epígrafes resultantes de la calificación que realiza la Clasificación Nacional de Actividades Económicas, CNAE, o similar)

I 2. Legislación aplicable a las actividades desarrolladas, ya sea la normativa legal, institucional y estatutaria a cumplir por la empresa.

I 3. Actividad en la que se enmarca la subvención recibida.

I 4. Normativa relacionada con las subvenciones recibidas.

I 5. Estructura organizativa, incluyendo un organigrama actualizado que permite identificar a los responsables de las diferentes áreas o departamentos.

I 6. Se detalla el perfil y trayectoria profesional de los miembros de la dirección y los responsables del gobierno de la entidad; por ejemplo, el presidente ejecutivo o consejero delegado y los miembros del Consejo de Administración/Gerencia o Alta Dirección.

I 7. Se especifica el perfil y trayectoria profesional de los responsables de las diferentes áreas o departamentos.

\section{Información económica, presupuestaria y estadística (7)}

I 8. Subvenciones y ayudas recibidas de una administración pública, con indicación de su importe y su finalidad.

I 9. Conocimiento del presupuesto completo de la actividad o el proyecto ya realizados o por desarrollar, no solo de la parte relativa a la subvención percibida, y la información actualizada y comprensible sobre el estado de ejecución de este.

I 10. Cuentas anuales individuales de la empresa.

I 11. Informe de gestión de la empresa.

I 12. Informes de auditoría externa de las cuentas anuales y, en su caso, del informe de gestión.

I 13. Retribuciones anuales percibidas por el presidente ejecutivo o consejero delegado y los miembros del Consejo de Administración. Indemnizaciones percibidas, en su caso, con ocasión del abandono del cargo.

I 14. Retribuciones anuales percibidas por los miembros de la Alta Dirección/Gerencia. Indemnizaciones percibidas, en su caso, con ocasión del abandono del cargo.

\section{Principios generales de divulgación en páginas web (10)}

I 15. Consta la fecha de la última actualización.

I 16. Información económica, presupuestaria y estadística de ejercicios anteriores. Al menos de los ejercicios $2017,2018,2019$ y $2020^{5}$.

I 17. Facilidad y gratuidad del acceso a la información sobre transparencia.

I 18. Existencia de una sección específica para las obligaciones de publicidad activa de la ley de transparencia, con información correctamente desglosada.

\footnotetext{
La mención de estos ejercicios se produce en el contexto de las obligaciones de publicidad activa recogidas en el reglamento de la ley de transparencia, y en cuanto a que los ejercicios anteriores sean cuatro años.
} 
I 19. Existe un contacto de dirección electrónica que responda a los requerimientos de información adicional o aclaratoria sobre las obligaciones de publicidad activa.

I 20. Se especifican las direcciones electrónicas de las áreas o departamentos de la empresa, donde se puede obtener explicaciones a la información publicada.

I 21. Documentos descargables en formatos reutilizables.

I 22. Existencia de un portal de transparencia para las obligaciones de publicidad activa de la ley de transparencia, sin restricciones de acceso.

I 23. La página de inicio contiene un mapa web, sin restricciones de acceso.

I 24. Existe un buscador en un lugar visible y destacado de la web.

I 25. Web adaptada a colectivos con discapacidad.

Fuente. Elaboración propia, a partir de la ley de transparencia y su reglamento

\subsubsection{Conexiones entre la propuesta de indicadores de la ley de transparencia y los indicadores del sistema español de acreditación de la transparencia, aplicables a entidades privadas de mercado}

La Asociación Española de Acreditación de la Transparencia (ACREDITRA) es una organización sin ánimo de lucro, constituida en diciembre de 2013, que tiene como finalidad promover la transparencia tanto de las organizaciones públicas como de las organizaciones privadas. Agrupa a las entidades que han asumido y están comprometidas con los más altos estándares en materia de transparencia, así como a consultores y auditores que trabajan en este campo.

La transparencia se interrelaciona con el gobierno abierto y el buen gobierno, retroalimentándose entre sí, para resultar en una mejora de la gestión y de la profundización en la calidad democrática y la accountability.

Dentro de sus objetivos destacamos dos:

- $\quad$ La evaluación de la transparencia de las administraciones públicas e instituciones privadas.

- $\quad$ La acreditación de transparencia de las administraciones públicas e instituciones privadas.

El diseño del sistema español de acreditación de la transparencia se considera una de las primeras iniciativas de medición y evaluación de la transparencia, con posterioridad a la publicación de la LTBG. Sierra (2014) describe los rasgos principales y sus características, si bien nunca se llegó a poner en marcha más allá de su experiencia piloto (Sierra, 2018:77). Merece especial mención que la revista española de transparencia, que promueve ACREDITRA, es citada como una revista de referencia en materia de transparencia, por el Consejo de la Transparencia y Buen Gobierno ${ }^{6}$.

El sistema se compone de 149 indicadores ${ }^{7}$, distribuidos en torno a 3 grandes áreas.

Los indicadores se han diseñado sobre un sistema de máximos, por lo que hay algunos que no son aplicables según la tipología de la organización. De esta forma, la relación de los 61 indicadores cuya aplicabilidad se circunscribe exclusivamente a las entidades privadas de mercado, se organizaría en torno a 2 grandes áreas, no siendo aplicables los 8 indicadores del área B) Derecho de acceso a la información pública, y a 13 agrupaciones.

Adicionalmente, para cada indicador, se distinguen 3 niveles de exigencia ${ }^{8}$ que se relacionan con el establecimiento de 3 niveles de acreditación, que se concede con una vigencia de 2 años:

- $\quad$ Nivel 1 Organización transparente, donde se publican todos los contenidos y se cumplen todos los principios de nivel 1 que se apliquen a la entidad por su naturaleza.

- Nivel 2 Organización referente, donde además del nivel 1, se publican los contenidos y se cumplen los principios correspondientes al menos, al $80 \%$ de los aspectos diferenciales correspondientes al nivel 2.

Nivel 3 Organización excelente, donde además del nivel 1, se publican los contenidos y se cumplen los principios correspondientes al menos, al $90 \%$ de los aspectos diferenciales correspondientes al nivel 2 y el $80 \%$ del nivel 3 .

Con el propósito de contrastar la elección de un conjunto representativo de indicadores y evitar solapamientos posteriores (en el diseño final del modelo), en la tabla 2 hemos recogido las relaciones que hemos detectado entre nuestra propuesta específica de indicadores de la ley de transparencia y los indicadores que utilizaría ACREDITRA en las áreas de publicidad activa y organización transparente, para las entidades privadas de mercado.

De forma complementaria se detallan: 
- Nuestros indicadores más específicos, recogidos en la tabla 1, a los que no hemos encontrado asociaciones manifiestas, aunque solo apreciamos diferencias de matiz en algunos: I 3; I 4; I 7; I 9; I 11; I 13; I 14; I 16; I 19 e I 25.

- $\quad$ Los 3 niveles de exigencia, mencionados anteriormente y siempre que proceda, de los indicadores de ACREDITRA, que son un total de 19.

Tabla. 2. Relaciones entre los indicadores de publicidad activa y los de ACREDITRA aplicables a empresas.

\begin{tabular}{|c|c|}
\hline \multicolumn{2}{|c|}{ Información institucional, organizativa y de planificación } \\
\hline I 1 & $\begin{array}{l}\text { A.01.01 Denominación y datos básicos de la entidad } \\
\text { Nivel 1: Publicar como contenidos mínimos la forma jurídica, el año de creación, los } \\
\text { Estatutos y/o normativa de creación y datos de contacto } \\
\text { A.01.02 Objeto y funciones de la entidad } \\
\text { Nivel } 1 \text { Publicar una descripción comprensible de la misión y funciones de la entidad } \\
\text { A.03.02 Funciones de los departamentos } \\
\text { Nivel } 1 \text { Publicar de forma suficientemente detallada las funciones de cada uno de los } \\
\text { departamentos de la entidad }\end{array}$ \\
\hline I 2 & $\begin{array}{l}\text { A.09.01 Normativa básica de organización y funcionamiento } \\
\text { Nivel } 1 \text { Publicar la normativa externa o interna más relevante que sea básica para el } \\
\text { funcionamiento de la entidad }\end{array}$ \\
\hline \multicolumn{2}{|c|}{ I 3 Actividad en la que se enmarca la subvención recibida } \\
\hline \multicolumn{2}{|c|}{ I 4 Normativa relacionada con las subvenciones recibidas } \\
\hline \multirow[t]{2}{*}{ I 5} & $\begin{array}{l}\text { A.02.01 Enumeración de los órganos de gobierno } \\
\text { Nivel } 1 \text { Incluir como mínimo, para cada órgano de gobierno, su denominación, funciones, } \\
\text { número de miembros y forma de elección de estos }\end{array}$ \\
\hline & $\begin{array}{l}\text { A.03.01 Organigrama general de la entidad } \\
\text { Nivel } 1 \text { Publicar un organigrama básico, indicando las áreas que están bajo la dependencia } \\
\text { de cada departamento/unidad } \\
\text { Nivel } 2 \mathrm{Si} \text { el organigrama es lo suficientemente completo y visual, indicando el número de } \\
\text { personas adscritas a cada departamento/unidad } \\
\text { Nivel } 3 \mathrm{Se} \text { incluye el nombre de la persona responsable de cada departamento/unidad }\end{array}$ \\
\hline \multirow{2}{*}{ I 6} & $\begin{array}{l}\text { A.02.02 Relación nominal de las personas integrantes de los órganos de gobierno y dirección } \\
\text { Nivel } 1 \text { Deberá publicarse como mínimo el nombre de la persona, cargo y funciones, fecha } \\
\text { de incorporación al órgano y relación de órganos en los que participa en representación de la } \\
\text { entidad, indicando la función que ejerce en dichos órganos }\end{array}$ \\
\hline & $\begin{array}{l}\text { A.02.03 Currículum actualizado de las personas integrantes de los órganos de gobierno y } \\
\text { dirección } \\
\text { Nivel } 1 \text { Datos mínimos a incluir, como nombre, año de nacimiento y máxima titulación } \\
\text { académica alcanzada; debiendo los currículums ser homogéneos en términos de contenidos y } \\
\text { extensión, entendiéndose que será mayor en los máximos responsables de cada órgano de } \\
\text { gobierno y dirección } \\
\text { Nivel } 2 \text { Se incluyen los aspectos más significativos de su trayectoria profesional, indicando } \\
\text { nombres de empresas o entidades, puesto y periodo de estancia, así como sus perfiles } \\
\text { públicos en redes sociales (si se tienen) }\end{array}$ \\
\hline \multicolumn{2}{|c|}{ I 7 Se especifica el perfil y trayectoria profesional de los responsables de las áreas o departamentos } \\
\hline \multicolumn{2}{|c|}{ Información económica, presupuestaria y estadística } \\
\hline I 8 & $\begin{array}{l}\text { A.07.04 Subvenciones y ayudas públicas recibidas } \\
\text { Nivel } 1 \text { Además del importe recibido y el objetivo o finalidad, se publica la entidad que } \\
\text { concede la ayuda y el procedimiento seguido para la concesión (concurrencia competitiva o } \\
\text { nominativa) }\end{array}$ \\
\hline \multicolumn{2}{|c|}{ I 9 Conocimiento del presupuesto y su estado de ejecución, relacionado con la subvención percibida } \\
\hline I 10 & $\begin{array}{l}\text { A.06.09 Cuentas anuales } \\
\text { Nivel } 1 \text { Para entidades privadas es suficiente con publicar balance y cuenta de resultados }\end{array}$ \\
\hline \multicolumn{2}{|c|}{ I 11 Informe de gestión de la empresa } \\
\hline I 12 & $\begin{array}{l}\text { A.11.02 Informes externos de auditoría y/o fiscalización } \\
\text { Nivel } 1 \text { Publicación de informes de auditoría externa de los últimos } 3 \text { años, o indicación } \\
\text { expresa de su no existencia }\end{array}$ \\
\hline \multicolumn{2}{|c|}{$\begin{array}{l}\text { I } 13 \text { Retribuciones anuales y posibles indemnizaciones con ocasión del abandono del cargo, del presidente } \\
\text { ejecutivo y los miembros del Consejo de Administración }\end{array}$} \\
\hline & .0 \\
\hline
\end{tabular}




\begin{tabular}{|c|c|}
\hline & $\begin{array}{l}\text { A.03.08 Convenio laboral } \\
\text { Nivel } 1 \text { Se publica el convenio o acuerdo de empresa que rige las relaciones laborales entre } \\
\text { la empresa y la plantilla }\end{array}$ \\
\hline \multicolumn{2}{|c|}{ Principios generales de divulgación en páginas web } \\
\hline I 15 & $\begin{array}{l}\text { C.02.03 Actualización suficiente de los contenidos de transparencia activa } \\
\text { Nivel } 1 \text { Con carácter general la información, sobre todo aquella de carácter económico, } \\
\text { deberá actualizarse con carácter trimestral y publicarse dentro del siguiente trimestre natural } \\
\text { Nivel } 2 \text { Los contratos o subvenciones, como una parte sustancial de los contenidos } \\
\text { económicos, están permanentemente actualizados, al estar vinculados con sistemas } \\
\text { informáticos }\end{array}$ \\
\hline \multicolumn{2}{|c|}{ I 16 Información económica, presupuestaria y estadística de los últimos 4 ejercicios } \\
\hline I 17 & $\begin{array}{l}\text { C.01.07 Gratuidad del acceso a la información sobre transparencia } \\
\text { Nivel } 1 \text { Publicación de posibles tasas solo en caso de expedición de copias o la trasposición } \\
\text { a un formato diferente al original }\end{array}$ \\
\hline $\begin{array}{l}\text { I } 18 \\
\text { I } 22\end{array}$ & $\begin{array}{l}\text { C.02.02 Portal de Transparencia o sección equivalente } \\
\text { Nivel } 1 \text { Alojamiento en este Portal de los indicadores del sistema o posibilidad de } \\
\text { direccionar a los diferentes contenidos de información relacionada }\end{array}$ \\
\hline \multicolumn{2}{|c|}{$\begin{array}{l}\text { I } 19 \text { Correo electrónico específico que responda a los requerimientos de información adicional o aclaratoria } \\
\text { sobre las obligaciones de publicidad activa }\end{array}$} \\
\hline \multirow[t]{2}{*}{ I 20} & Posibles explicaciones a la información publicada por parte de las áreas o departamentos \\
\hline & $\begin{array}{l}\text { A. } 03.03 \text { Contacto de los departamentos } \\
\text { Nivel } 1 \text { Publicación de los correos genéricos de atención de los departamentos que tengan } \\
\text { relación con la ciudadanía, clientes y grupos de interés }\end{array}$ \\
\hline I 21 & $\begin{array}{l}\text { C.01.05 Reutilización de documentos } \\
\text { Nivel } 1 \text { Posible acceso a formularios y modelos que la ciudadanía y grupos de interés } \\
\text { pudiesen reutilizar en sus relaciones con la entidad } \\
\text { C.01.06 Reutilización de datos cuantitativos } \\
\text { Nivel } 1 \text { Posibilidad de exportación de datos cuantitativos, tablas y estadísticas a hojas de } \\
\text { cálculo o instrumentos análogos }\end{array}$ \\
\hline I 23 & C.01.04 Web amigable y comprensible \\
\hline I 24 & $\begin{array}{l}\text { Nivel } 1 \text { Información disponible de manera clara, estructurada y entendible para las personas } \\
\text { interesadas }\end{array}$ \\
\hline
\end{tabular}

Fuente. Elaboración propia

\section{2. Área de transparencia relacionada con información publicada. Los principios de transparencia y prevención de la corrupción para las empresas (TI-España)}

En torno al sector privado, la representación en España de Transparencia Internacional (TI-España) elaboró y publicó los "Principios de Transparencia y Prevención de la Corrupción para las empresas" con la finalidad de establecer patrones de actuación que ayuden a las compañías a desarrollar sus actividades con transparencia y responsabilidad social.

El número 6. Información pública de las contrataciones con el sector público e información de las actividades subvencionadas con ayudas públicas va en línea con la obtención de lograr un sistema de transparencia e información para la prevención de la corrupción en las administraciones públicas, pero también en la consecución de valor en la actividad empresarial. La publicidad se puede dar por ejemplo a través de la página web corporativa.

Este principio supone un claro antecedente de la legislación actual en la transparencia de las empresas que reciben subvenciones, que hemos relatado previamente.

\subsubsection{Conexiones entre los principios de transparencia y prevención de la corrupción para las empresas y los indicadores del sistema español de acreditación de la transparencia, aplicables a entidades privadas de mercado}

En la tabla 3 hemos recogido un total de 12 indicadores que manejaría ACREDITRA en las áreas de publicidad activa y organización transparente, para las entidades privadas de mercado, que pueden enlazarse con los 10 principios de transparencia y prevención de la corrupción para las empresas de TI-España, que aparecen numerados del 1 al 10. 
También, de forma complementaria, se explicita la posible inclusión de los principios en nuestra propuesta final de indicadores para el área de transparencia relacionada con la información obligatoria a publicar, en base a la LTBG:

Tabla. 3. Relaciones entre los indicadores para el área 2 de transparencia y los de ACREDITRA aplicables a empresas.

\section{Cumplimiento de los Principios de Buen Gobierno Corporativo}

C.01.01 Código de Buen Gobierno o Código Ético

Nivel 1 Existencia de un código externo de aplicación que deberá publicarse e indicarse la fecha y forma de su adhesión

\section{Implementación en la Empresa de un Código Ético}

C.01.01 Código de Buen Gobierno o Código Ético

Nivel 1 Existencia de un código propio de aplicación que deberá publicarse e indicarse la fecha y forma de su aprobación

3. Implementación de Programas de cumplimiento normativo (Compliance Programmes)

\section{A.9) NORMATIVA}

A.09.01 Normativa básica de organización y funcionamiento

I 2 Legislación aplicable a las actividades desarrolladas, ya sea la normativa legal, institucional y estatutaria a cumplir por la empresa.

A.09.04 Resoluciones judiciales de aplicación

Nivel 1 Publicación de las principales resoluciones judiciales que afectan a la entidad y que pueden servir como "jurisprudencia" en la relación entre la entidad y sus grupos de interés, o mención expresa de su no existencia A.09.05 Directrices, instrucciones, acuerdos, circulares y respuestas a consultas con efectos jurídicos

Nivel 1 Publicación de las principales directrices, instrucciones, acuerdos, circulares y respuestas a consultas con efectos jurídicos que puedan ser de interés para los grupos de interés que se relacionan con la entidad, o mención expresa de su no existencia

C.01.02 Régimen sancionador en materia de Buen Gobierno

Nivel 1 Deberá publicarse la normativa relevante en materia de sanciones por incumplimiento del buen gobierno, bien sea la normativa propia de la entidad o del grupo al que pertenece o bien sea la externa aplicable, ya sea estatal, autonómica u otras posibles

C.01.03. Normativa reguladora de transparencia

Nivel 1 Publicación de la normativa relevante de aplicación a la entidad en materia de transparencia, bien la normativa propia de la entidad o del grupo al que pertenece o bien sea la externa, estatal, autonómica u otras posibles

4. Implementación de canales de denuncias para la comunicación de posibles incumplimientos de las normas internas de la empresa y/o de las normas legales

A.2) ÓRGANOS DE GOBIERNO Y CARGOS DE REPRESENTACIÓN/DIRECCIÓN

A.02.04 Datos de contacto de las personas integrantes de los órganos de gobierno y dirección

Nivel 1 Se deberá incluir como mínimo un correo electrónico personalizado o un formulario web que remita a dicha cuenta personal para todas las personas integrantes de los órganos de gobierno y dirección

A.4) RELACIONES CON LA CIUDADANÍA Y LOS GRUPOS DE INTERÉS

A.04.01 Oficinas presenciales de atención a la ciudadanía y grupos de interés

Nivel 1 Se publica la relación de dichas oficinas de atención

A.04.02. Horarios de atención

Nivel 1 Se publican los horarios de atención en dichas oficinas presenciales

A.04.03 Webs y Portales electrónicos

Nivel 1 Se publica una relación de los que dispone la entidad

A.04.13 Quejas y sugerencias

Nivel 1 Se posibilita el acceso a la sección web de quejas y sugerencias, con posibilidad de realizarlas de forma telemática

Nivel 2 Se publica un informe resumen sobre las quejas y sugerencias realizadas, indicando aspectos como número total, principales cuestiones planteadas, medidas correctoras tomadas...

Nivel 3 Se publican las quejas y sugerencias realizadas

\section{Información pública de las retribuciones de los directivos y administradores}

ACREDITRA relaciona los indicadores A.02.07 y A.02.11 como no aplicables a entidades privadas de mercado:

A.02.07 Retribuciones económicas percibidas por las personas integrantes de los órganos de gobierno

A.02.11 Indemnizaciones y pensiones percibidas por el abandono de las y los altos cargos

I 13 Retribuciones anuales y posibles indemnizaciones con ocasión del abandono del cargo, del presidente 
ejecutivo y los miembros del Consejo de Administración

I 14 Retribuciones anuales y posibles indemnizaciones con ocasión del abandono del cargo, de los miembros de la Alta Dirección/Gerencia

6. Información pública de las contrataciones con el sector público e información de las actividades subvencionadas con ayudas públicas

ACREDITRA:

- Desarrolla el área A.5) CONTRATACIÓN para instituciones públicas y otro tipo de entidades públicas y entidades sujetas a derecho público; no siendo aplicable a entidades privadas de mercado

- No contempla ningún indicador para las actividades subvencionadas con ayudas públicas

I 3 Actividad en la que se enmarca la subvención recibida

\section{Información pública de las políticas de Responsabilidad Social Corporativa}

A.08.05 Memoria general de la entidad

Nivel 1 Se publica un Informe o Memoria de Sostenibilidad, relacionada con sus estrategias de RSC, que explique las actividades desarrolladas y sus principales indicadores de desempeño

8. Evitación de prácticas de favorecimiento y corrupción en el sector privado

\section{A.11) CONTROLES FORMALES}

A.11.01 Informes internos de Intervención y Auditoría de Cuentas

Nivel 1 Publicación de los informes de auditoría de cuentas emitidos por parte de los correspondientes órganos de control interno de la entidad en los últimos 3 años, siguiendo como criterio temporal la fecha de publicación del informe

A.11.02 Informes externos de auditoría y/o fiscalización

Nivel 1 Publicación de informes de auditoría externa de los últimos 3 años, o indicación expresa de su no existencia

I 12 Informes de auditoría externa de las cuentas anuales

9. Evitación de prácticas de corrupción de funcionarios extranjeros en las transacciones internacionales

Indicadores similares que para el principio anterior

10. Cumplimiento de las obligaciones fiscales

Relación con otros indicadores ya enumerados:

C.01.01

A.9) NORMATIVA

A.11) CONTROLES FORMALES

Fuente. Elaboración propia

\section{3. Área de transparencia relacionada con información publicada. Desarrollo de las tres dimensiones de la RSC y otras áreas afines de reporting corporativo}

En este caso se ha tomado como reseña inicial a los indicadores del sistema español de acreditación de la transparencia para 2016, aplicables a entidades privadas de mercado.

Se han agrupado en la tabla 5 los 16 indicadores que se relacionarían con las tres dimensiones de la Responsabilidad Social Corporativa (RSC), básicamente dentro del área de publicidad activa:

La configuración originaria de esta área 3 de nuestro modelo TESUB servirá a las empresas que reciben subvenciones para poder acreditarse en transparencia, y de esta forma evitar dobles esfuerzos en la configuración de la información necesaria.

Tabla. 4. Indicadores para el área 3 de transparencia de TESUB.

Indicadores de la dimensión económica

A.6) INFORMACIÓN ECONÓMICO-FINANCIERA Y PATRIMONIAL GENERAL (7)

A.06.10, A.06.11, A.06.12, A.06.13, A.06.14, A.06.15 y A.06.16

A.06.10 Resumen comprensible de las cuentas anuales

Nivel 1 Se publican las cuentas de la entidad de forma comprensible y en un lenguaje adaptado a los conceptos que entiende la ciudadanía

A.06.11 Endeudamiento

Nivel 1 Se publica el importe total del endeudamiento de la entidad, un desglose entre endeudamiento comercial y financiero, el importe de las deudas con Hacienda, la Tesorería General de la Seguridad Social y otras administraciones públicas y el endeudamiento atribuible por la participación de la entidad en otras entidades en las que tiene participación societaria

A.06.12 Deuda financiera 
Nivel 1 Se especifica expresamente el importe de la deuda financiera, incluyendo una relación de las diferentes líneas de financiación, indicando para cada una de ellas, como mínimo, el nombre de la entidad financiadora, la financiación total recibida, las condiciones de financiación (fecha de amortización y sus características básicas, como tipo de interés nominal, periodos de carencia, ...) y el saldo vivo actual

A.06.13 Evolución del endeudamiento

Nivel 1 Se publican datos acerca de la evolución del endeudamiento en comparación con ejercicios anteriores

A.06.14 Ratios de endeudamiento

Nivel 1 Se publican los ratios más relevantes en relación con el endeudamiento, como el endeudamiento relativo, entendido como el porcentaje de fondos ajenos en relación con la cifra de ingresos del último ejercicio cerrado y en relación con los fondos propios y el endeudamiento unitario = endeudamiento en relación con una unidad de medida de personas que se considere razonable en función de la tipología de la entidad

A.06.15 Plazo de pago a proveedores

Nivel 1 Se publica la información sobre el plazo de pago a proveedores, indicando la evolución del mismo

A.06.16 Ratios económico-financieros

Nivel 1 Se publican los principales ratios económico-financieros de la entidad, acompañados de una explicación en formato comprensible que permita su interpretación

Indicadores de la dimensión medioambiental

A.10) URBANISMO, OBRAS Y MEDIO AMBIENTE (2)

A. 10.09 y A. 10.11

A.10.09 Sanciones ambientales recibidas

Nivel 1 Se publica la relación de las sanciones firmes recibidas en los últimos 5 años por incumplimiento de la normativa medioambiental, publicando como mínimo la entidad sancionadora, el importe de la sanción y el motivo de la sanción

A.10.11 Indicadores ambientales

Nivel 1 Se deberán publicar los indicadores sobre el consumo de recursos (energía, agua, ...). En el caso de entidades que desarrollen actividades potencialmente nocivas, deberá informarse además sobre aspectos como las emisiones de $\mathrm{CO} 2$ y otras relevantes

Indicadores de la dimensión social

A.3) ORGANIZACIÓN Y RECURSOS HUMANOS (3)

A.03.04, A.03.05 y A.03.15

A.03.04 Relación de Puestos de Trabajo

Nivel 1 Se deberá publicar al menos la plantilla total de la entidad en el último ejercicio cerrado, indicando su distribución total por niveles profesionales y departamentos

A.03.05 Oferta de empleo

Nivel 1 Deberá informarse sobre los canales de selección que utiliza la empresa y posibilitarse un procedimiento (dirección electrónica, formulario web, ...) para que las personas interesadas puedan remitir sus candidaturas

A.03.15 Liberaciones similares

Nivel 1 Se publica la información global sobre esta materia, indicando como mínimo: los sindicatos a los que pertenecen, el número de personas liberadas, los porcentajes de liberación y el coste económico, en términos de salario bruto, de dichas liberaciones; si no existen, deberá indicarse expresamente

A.4) RELACIONES CON LA CIUDADANÍA Y LOS GRUPOS DE INTERÉS (3)

A.04.05, A.04.11 y A.04.12

A.04.05 Asociaciones y grupos de interés

Nivel 1 Se mencionan las principales tipologías de grupos de interés (stateholders) con los que interactúa la entidad, sin indicación expresa de sus nombres

A.04.11 Guía de procedimientos y Trámites y/o Catálogo de Servicios

Nivel 1 Se informa suficientemente sobre los servicios que ofrece la entidad

A.04.12 Cartas de Servicios

Nivel 1 No obligatorio si no existen. En tal caso, se indicará de forma expresa

Nivel 2 Existen y se publican las Cartas de Servicios disponibles en la entidad

Nivel 3 Se publican los resultados de las evaluaciones de los compromisos establecidos en dichas Cartas

C.1) COMPROMISO Y PRINCIPIOS GENERALES DE TRANSPARENCIA Y BUEN GOBIERNO (1) C.01.09

C.01.09 Igualdad de género

Nivel 1 Se publica al menos la desagregación por sexo de los siguientes indicadores. Número de altos cargos, número de cargos de confianza y plantilla

Nivel 2 Se ofrece desagregación por sexo de los indicadores relevantes de la actividad externa de la entidad

Nivel 3 Se realizan y publican, además, evaluaciones con perspectiva de género en aquellas materias relevantes que afectan a personas físicas

Fuente. Elaboración propia, a partir del Sistema Español de Acreditación de la Transparencia 


\section{La metodología MESTA como referente del modelo TESUB}

Una de las funciones encomendadas por la ley de transparencia al CTBG consiste en evaluar el grado de cumplimiento de esta por los sujetos comprendidos en sus arts. 2 y 3 .

Respecto de los ejercicios 2015, 2016 y 2017 se ha centrado en las administraciones y entidades públicas, y se ha excluido a las entidades privadas por una serie de razones, citándose la limitación de los recursos humanos y materiales del Consejo y por ser un grupo muy numeroso sin existir actualmente bases de datos que faciliten su identificación (CTBG, Memoria de actividades del año 2018: 93).

Aunque el sistema MESTA pretendía ser un sistema que se aplicara de forma más o menos extendida, no ha sido puesto en práctica de manera generalizada "y la proactividad y liderazgo que sería esperable en esta materia por el CTBG no se está produciendo" (Sierra, 2018: 79), la propuesta de nuestro modelo específico de Transparencia de las Empresas que reciben Subvenciones (TESUB) se va a apoyar en la metodología MESTA, como instrumento de medición tanto cuantitativo como cualitativo, partiendo de la premisa de lo que supone la publicidad activa como: "Obligación de los sujetos que determina la Ley de publicar, de forma proactiva y en las condiciones establecidas, los datos o informaciones que sean relevantes para garantizar la transparencia de su actividad y, en todo caso, los designados expresamente en la norma, con vistas a posibilitar el ejercicio por la ciudadanía de su derecho a la participación y al control de los asuntos públicos"(CTBG, Criterio interpretativo 2/2019, sobre el concepto y la naturaleza de la publicidad activa).

Se trata de medir, en primer lugar, los mínimos de contenido que se corresponden con la relación de información objeto de publicidad activa establecidos en la LTBG, eso sí, específicos para entidades privadas, siguiendo con el resto de las áreas de transparencia que hemos establecido.

Se busca superar las debilidades de tipo metodológico ya detectadas en las mediciones de transparencia de las entidades públicas, donde sigue existiendo el problema de que los indicadores se centran principalmente en la cantidad de información disponible (Ros, 2018), que solo son "una simple comprobación de la publicación de una información en la web" (Delgado, López y Sierra, 2015:125) sin tener en consideración el cumplimiento de los principios generales de la publicidad activa, sin cuyo cumplimiento no habría transparencia posible (García Melián, 2017).

En línea con la definición de publicidad activa, MESTA contempla la medición de la información publicada (contenidos, forma y actualización), los atributos de dicha información (accesibilidad, claridad/comprensibilidad, estructura y reutilización) y del soporte web donde se aloja. Tiene en cuenta lo que denomina el mapa de publicidad activa de cada organismo (en nuestro caso sería de la tipología de empresa en cuestión), que diferencia entre la información obligatoria según la LTBG y el resto de información según sea aplicable a la entidad concreta sobre la que se va a medir la transparencia.

En nuestro modelo TESUB, fijándonos en MESTA en lo referente a la metodología de medición en materia de publicidad activa, se va a evaluar el grado de cumplimiento obligatorio de la ley de transparencia y a continuación se trataría de evaluar la calidad de la transparencia de la información publicada en general, para el conjunto de empresas grandes de una muestra, con indicadores voluntarios añadidos a los obligatorios, dentro de nuestro contexto empresarial específico.

Nuestro modelo aspira a medir qué se publica y cómo se publica, con valoraciones que atiendan a la calidad de la información y al soporte web, como propugna MESTA.

Como expresan Molina, Simelio y Corcoy (2017), entendemos que trasladable a cualquier entidad y no solo a administraciones públicas, las evaluaciones variarán en función del objetivo de evaluación, de la definición de transparencia que se maneje y de los usuarios o destinatarios.

Parris, Dapko, Arnold y Arnold (2016) han analizado los artículos publicados en los últimos 30 años sobre el tema de la transparencia organizacional, llegando a la conclusión que en la mayoría de las definiciones de transparencia en las organizaciones se incluyen las ideas de apertura interna y externa y acceso a la información codificada y acumulada por la organización para que se produzca el conocimiento compartido con los grupos de interés.

El concepto transparencia dependerá de los criterios con los que se evalúa en un contexto y entorno dado; en nuestro caso es un modelo específico que aplicaremos en empresas grandes cotizadas y no cotizadas, que reciben subvenciones. El contexto ahora establecido irá evolucionando con el paso del tiempo y exigirá que se vayan adaptando las mediciones.

Con la consideración de las tres áreas de transparencia estamos marcando la pauta de qué ha de medir TESUB, que acaba determinando las características del procedimiento y cuáles son los objetivos de la evaluación:

1. En primer lugar, nos interesa un índice de información o transparencia que estaría alineado con un control desde el punto de vista del cumplimiento de las obligaciones legales. Destaquemos que una de las causas de reintegro de subvenciones previstas en la ley general de subvenciones (artículo 37, apartado f) LGS) podemos interpretar que va asociado al cumplimiento específico de alguno de los indicadores enumerados en la tabla 1, como son el I 8 y el I 9, aparte de que el cumplimiento de las 
obligaciones legales se puede incluir como un supuesto previsto en la normativa reguladora de una subvención concreta. En el ámbito de empresas receptoras de subvenciones se manifiesta con mayor trascendencia, al tratarse en muchos casos de beneficiarios recurrentes varios años, y se tiene la intención de contrastar si una de las variables que lo explican es el importe de subvenciones concedidas.

2. Valorar la transparencia con relación a la corrupción.

3. Vincular la RSE y la transparencia, en relación con ir más allá de las obligaciones legales, que pasa por definir adecuadamente los indicadores de información no obligatoria, donde ocupan un lugar destacado los referidos a la información no financiera, que complementan a la información económica y financiera como un medio fundamental de comunicación con los diferentes agentes externos interesados en la situación y evolución de las entidades privadas.Respecto a los contenidos no obligatorios de empresas grandes, van a cambiar próximamente y conducen a un concepto dinámico en las entidades de nuestro futuro estudio, y en sus destinatarios o grupos de interés, por lo que el diseño del modelo deberá ir adaptándose en el tiempo.

\section{Diseño y aplicabilidad del modelo TESUB}

Vamos a explicitar la definición y los cálculos necesarios para establecer los diferentes índices de evaluación:

1. Índice del Cumplimiento en Publicidad Activa (ICPA).

2. Índice de Transparencia y Prevención de la Corrupción (ITPC).

3. Índice de Transparencia en Publicidad Activa (ITPA).

Posteriormente, se pasaría a la recogida de los datos de las páginas web de las empresas de una muestra en cada una de las tres áreas de transparencia, dentro de una metodología cuantitativa y cualitativa.

Cabe mencionar que MESTA utiliza unos cuestionarios cumplimentados por agentes externos a la entidad o por la propia entidad para realizar autoevaluaciones, mientras que nosotros nos apoyamos en la metodología, pero utilizaremos la técnica del análisis de contenidos de las páginas web.

En cada una de las tres áreas de transparencia vamos a definir un índice de evaluación, comenzando por el ICPA, llegándose por sucesivas integraciones a los índices de evaluación ITPC e ITPA definidos en las áreas 2 y 3 respectivamente.

En este sentido, y dependiendo en que bloque nos posicionemos, nos alineamos con estudios que distinguen índices de revelación de información obligatoria o voluntaria, como Street y Bryant (2000) o Angla, Rodríguez y Vidal (2002), pero también con los estudios que no realizan esta distinción, bien porque los ítems informativos son del mismo tipo o por desaparecer esta diferenciación si se calcula un índice de divulgación total, como los de Cooke (1989); García y Monterrey (1993); Wallece, Naser y Mora (1994); Gray, Kouhy y Lavers (1995); Archel (2001); Espinosa y Sabater (2002) y Vanstraelen , Zarzeski y Robb (2002) entre otros.

Formando parte del cálculo de los índices de evaluación mencionados, en cada área hay un indicador específico relacionado no solo con los contenidos sino también con la forma, la actualización de la publicación y los atributos de la información.

Cada indicador específico relacionado solo con los contenidos publicados va en la línea de la fórmula habitual de recurrir a indicadores dicotómicos (si/no, cumple/no cumple), que son más fáciles de aplicar al no ser ponderados. Según la empresa suministre o no una determinada información las variables toman los valores 1 o 0 , de acuerdo con trabajos anteriores en los que se ha evaluado la información suministrada por las empresas a través de Internet (Ettredge, Richardson y Scholz, 2002), que conforman un índice no ponderado que evita la arbitrariedad inherente a este proceso (Giner, 1997), ya que el empleo de índices con o sin ponderación no altera las conclusiones obtenidas (Chow y Wong-Boren, 1987), no resultando adecuada la ponderación de variables ya que implica la introducción de un cierto grado de subjetividad (Firth, 1980).

Alguno de los criterios referidos a los atributos de la información y al soporte web son más complejos de valorar, pero son también los que nos van a permitir captar una gradación y construir de una forma más adecuada unos indicadores finales que redundarán en un modelo final TESUB con mayores fortalezas metodológicas.

Como posteriormente se expondrá, para la obtención del valor total de los índices de evaluación, se ha considerado que las ponderaciones de cada uno de sus componentes sean proporcionales a los 10 criterios de medición definidos en la metodología.

Entre los trabajos donde la ponderación de los ítems informativos contribuye a la elaboración del valor del índice de revelación se encuentran los de Buzby (1975), que obtiene la ponderación a través de escalas de valoración, que dividen cada ítem en distintos subconceptos informativos a los que se asigna un peso; Lang y 
Lundholm (1993) emplean como ponderación la que asignan los analistas financieros; Carmona y Carrasco (1998) establecen la puntuación de acuerdo con la tipología de la información, apreciando que además de datos actuales se ofrezcan informes históricos o previsiones; Gandía (2000), Larrán y Giner (2001) tienen en cuenta las características de la información disponible, tales como la accesibilidad y navegabilidad de la página web; Sierra y Rojo (2002) mediante encuestas.

El entendimiento de la explicación del procedimiento a seguir pasa en primer lugar por la descripción de los criterios de medición, para llegar a cada uno de los índices mencionados.

\subsection{Criterios de medición necesarios para el Índice del Cumplimiento en Publicidad Activa (ICPA)}

Se van a considerar un total de 10 criterios de medición, que vamos a numerar del $\mathrm{C} 1$ al $\mathrm{C} 10$, y cada uno se puntúa de forma similar, con un máximo de 100 puntos, puesto que la ley de transparencia no establece ninguna distinción entre estos.

No obstante, en línea con la propuesta de mejora para MESTA realizada por Ros (2018) conviene resaltar que haremos depender las variables de calidad de la variable de cantidad, de forma que la falta de publicación de un determinado contenido conllevaría un cero de puntuación, ya que esta circunstancia supondría una falta total de transparencia, para evitar de esta forma el posible sesgo que se pudiera producir al valorar por igual las 10 variables que manejamos nosotros.

El componente de la información tiene un total de 7 criterios:

- $\quad 3$ criterios referentes a la publicación: $\mathrm{C} 1, \mathrm{C} 2$ y C3.

- $\quad 4$ criterios relativos a los atributos: C4, C5, C6, C7.

Respecto al soporte web son 2 los criterios asociados que pueden condicionar la disponibilidad de los datos: $\mathrm{C} 8$ y $\mathrm{C} 9$ y adicionalmente se ha considerado el criterio $\mathrm{C} 10$.

A continuación, se conexiona cada criterio con cada uno los indicadores de la ley de transparencia relacionados con la publicidad activa de las empresas que reciben subvenciones expresados en la tabla 1 para facilitar la comprensión de lo que valora cada criterio, a modo de listado de informaciones que deben ser objeto de publicación con unos principios de divulgación en páginas web. Seguidamente se explica la fórmula de cálculo y la definición de los valores que pueden adoptar, lo que garantizará la validez de la metodología y evitará diferentes interpretaciones que pudieran distorsionar la posterior recogida de datos.

\subsubsection{Criterios de publicación de la información}

En este grupo se encuentran básicamente los referidos al contenido de la publicación de la información mínima y obligatoria que a la que la entidad está obligada. Dentro de las condiciones de la publicación se incluye la actualización de la información y el modo en el que se presenta.

\section{Contenido de la publicación: C1}

Los diferentes indicadores de información vienen establecidos en la LTBG. Abarcan desde I 1 hasta I 14 en la tabla 1.

Descripción

Mide la proporción (\%) de los contenidos obligatorios publicados en la página web de la empresa respecto del total de información exigida, ya sea información institucional, organizativa y de planificación (I 1 a I 7) e información económica, presupuestaria y estadística (I 8 a I 14).

Fórmula de cálculo

Suma de los diferentes indicadores, que toman el valor 1 si el ítem de información se encuentra publicado y 0 en caso contrario, dividido por 14, que es el total de número de indicadores que se han establecido, y multiplicado por100.

Definición de los valores

Cualquier valor dentro del intervalo 0-100. Un 100 revela que ha publicado el $100 \%$ de la información que le es aplicable y requerida, mientras que un 0 muestra que no ha publicado ninguna información.

\section{Forma de la publicación: $\mathrm{C} 2$}

En referencia a los medios de publicación de subvenciones, como todas las empresas pueden cumplir con todas sus obligaciones utilizando los medios de publicidad electrónicos de la organización, asociación, agrupación u organizaciones representativas o sectoriales a las que pudieran pertenecer, se presenta la doble alternativa de una publicación de forma directa en la propia página web, o indirecta, con enlaces al lugar específico donde se encontraría la información.

Descripción

Mide la proporción (\%) de los contenidos obligatorios publicados de forma directa en la página web de la empresa respecto del total de información exigida. El resto de proporción hasta llegar al $100 \%$ significaría el contenido publicado a través de un enlace. 
Fórmula de cálculo

De forma complementaria a los contenidos, se sitúa al "ciudadano" (analista) previamente en el lugar en el que se encuentra la información, considerando el número de indicadores que se encuentran en la web propia sobre el total de 14.

Definición de los valores

Cualquier valor dentro del intervalo 0-100. Un 100 revela que la totalidad de la información exigida se muestra de forma directa, mientras que un 0 representa que toda la información publicada se hace de forma indirecta.

\section{Actualización de la publicación: C3}

1 15. Consta la fecha de la última actualización.

I 16. Información económica, presupuestaria y estadística de ejercicios anteriores. Al menos de 4 últimos ejercicios.

En lo referente a la información institucional, organizativa y de planificación, hace alusión a su puesta al día, a su renovación, por lo que deberá ser la última disponible sobre esta materia.

En lo relativo a la información económica, presupuestaria y estadística, estará establecida en el ejercicio siguiente, antes del 31 de enero, a aquel en que se superen los umbrales establecidos de subvenciones recibidas, que marcan las obligaciones de publicidad activa; si nos atenemos a lo preceptuado en el reglamento de desarrollo de la ley de transparencia (artículo 14. Obligaciones de publicidad activa).

Se entiende que la información es periódica cuando sea divulgada en el periodo de tiempo temporal que le corresponde, debiendo permanecer publicada durante los cuatro años naturales siguientes.

Descripción

Mide si la información dispone de fecha de actualización y si se divulga en cumplimiento de la legislación vigente, referida al ámbito temporal que corresponda en cada caso.

Fórmula de cálculo

El analista visualizará en la web si existe una fecha de actualización de la información. Para el cumplimiento de lo establecido en materia de publicidad activa, en cuanto a superar los importes de subvenciones recibidas, se pueden contrastar los datos ofrecidos por la empresa con la información pública y oficial que se encuentra en la BDNS (Base de Datos Nacional de Subvenciones).

Definición de los valores

Un valor 100 significa que se especifica la fecha de actualización y que la empresa cumple con la legislación vigente, respetando la disposición de la información durante los cuatro años naturales siguientes.

Un valor 50 representa que se declara la fecha de actualización y que se publica exclusivamente lo relativo al último ejercicio de obligación.

Un valor 0 denota que no se produce la actualización de la publicación en ningún sentido.

\subsubsection{Atributos de la información}

En este grupo se localizan los concernientes a los atributos de la información publicada y por tanto van ligados a la calidad de esta desde la perspectiva del ciudadano, sin considerarse el contenido técnico.

\section{Accesibilidad: C4}

I 17. Facilidad y gratuidad del acceso a la información sobre transparencia.

Descripción

La facilidad de accesibilidad se cumple en función del número de clics necesarios para acceder a la información, comenzando a contar desde la página inicial de acceso a la web de la empresa considerada, dando por hecho la gratuidad de los datos suministrados si está disponible.

Fórmula de cálculo

Se realiza una clasificación por intervalos dependiendo del número de veces que es necesario cliquear para llegar a la información, asignando los valores de forma inversa al número de clics.

Definición de los valores

Se asigna un valor de 100 si el número de clics es hasta 3 y un valor 0 si es superior a 12 .

Si el número de clics es 4 se le asigna un 90 , si es 5 un 80 y así sucesivamente hasta asignar el valor 10 para 12 clics.

\section{Estructurada: C5}

I 18. Existencia de una sección específica para las obligaciones de publicidad activa de la ley de transparencia, con la información correctamente desglosada.

El hecho de contar con una sección o apartado en la página web es un primer paso, siendo valorable, como mínimo, que existan títulos identificativos de los bloques de contenido.

Descripción

Cuantifica como está organizada y ordenada la información. 
Fórmula de cálculo

Se efectúa una puntuación entre 0 y 100 en función de la apreciación sobre la presentación de la información, de forma que permita una lectura ordenada y organizada.

Definición de los valores

El valor 100 determina que toda la información se encuentra en una única zona y bajo una rúbrica exclusiva, con títulos identificativos de los bloques de información institucional, organizativa y de planificación y de información económica, presupuestaria y estadística. Progresivamente de mayor a menor organización se llegaría al valor 0 , que señala que toda la información se encuentra dispersa en diferentes apartados de la página web.

\section{Claridad: C6}

I 19. Existe un contacto de dirección electrónica que responda a los requerimientos de información adicional o aclaratoria sobre las obligaciones de publicidad activa.

I 20. Se especifican las direcciones electrónicas de las áreas o departamentos de la empresa, donde se puede obtener explicaciones a la información publicada.

La valoración del lenguaje utilizado en el contenido de la información puede resultar bastante subjetiva, a pesar de que existan tutoriales, glosarios o comentarios aclaratorios, en el caso de utilizar un lenguaje complejo. Por consiguiente, una posible forma de explicación es dar la posibilidad de contactar con la empresa, poniendo a disposición de los usuarios direcciones electrónicas y encargados de las mismas en este contexto.

Descripción

Mide la comprensibilidad del lenguaje manejado en el contenido de la información, principalmente a través de los contactos facilitados para conseguir posibles aclaraciones.

Fórmula de cálculo

Se realiza una puntuación entre 0 y 100 en función de la calificación del lenguaje, de los posibles tutoriales y sobre todo de la existencia de correos electrónicos a los que poder dirigirse si la información es muy técnica y precisa clarificarse.

Definición de los valores

El valor 100 expresa que la información es muy comprensible o por lo menos se facilitan los contactos que pueden realizar las aclaraciones oportunas y gradualmente de mayor a menos claridad se llegaría al valor 0 , que dice que la información no es nada clara y no se detalla ningún posible acceso a las explicaciones oportunas.

\section{Reutilización: C7}

I 21. Documentos descargables en formatos reutilizables; por ejemplo, txt, csv, xml.

El referente sobre el formato de la información que se publica se encuentra en la Ley 37/2007, de 16 de noviembre, sobre reutilización de la información del sector público, y en su normativa de desarrollo.

Descripción

Mide la proporción de los contenidos publicados que se encuentran en formatos reutilizables con respecto al total de la información publicada.

Fórmula de cálculo

Se acomete una puntuación entre 0 y 100 en función de la evaluación de los documentos descargables que lo son en formatos reutilizables.

Suma de los diferentes indicadores, que toman el valor 1 si el ítem de información se encuentra publicado en formato descargable y 0 en caso contrario, dividido por el número total de indicadores publicados, y multiplicado por 100 .

Definición de los valores

Cualquier valor dentro del intervalo 0-100. El valor 100 representa que el $100 \%$ de la información publicada está en formatos reutilizables, mientras que el valor 0 simboliza que nada de la información publicada está en formatos reutilizables.

\subsubsection{Soporte web: consideramos 3 criterios}

El canal que se utiliza para la publicación es el tercer componente de la publicidad activa. Los criterios ligados a las webs pueden condicionar la disponibilidad y la transparencia de la información, que también consiste en poner los medios adecuados para facilitar el acceso a la información divulgada, su identificación y localización.

\section{Lugar de la publicación: C8}

I 22. Existencia de un portal de transparencia para las obligaciones de publicidad activa de la ley de transparencia, sin restricciones de acceso. 
Sería deseable que las entidades privadas implantasen un portal de transparencia en la web institucional, a modo de sección específica de transparencia, que sea visible en la propia portada de inicio y donde la información se pueda conseguir sin precisarse permisos previos.

Descripción

El lugar concreto o sección debe contener la palabra "transparencia". Su uso debe permitir, a través de un único punto de acceso, el que un ciudadano pueda obtener toda la información disponible sobre la que existe una obligación de publicidad activa.

Fórmula de cálculo

Responder a las cuestiones sobre si se dispone de un apartado específico de transparencia, que tomará el valor 1 en caso afirmativo y de si está en la página de inicio, donde nuevamente tomará el valor 1. Finalmente se sumarán ambas valoraciones y el resultado se multiplicaría por 50.

Definición de los valores

Un valor 100 significa la existencia en la página de inicio de la empresa de un apartado específico de transparencia, donde se ubica la información de publicidad activa.

Un valor 50 representa la existencia de un apartado específico de transparencia en la página web de la empresa, pero no en su página de inicio.

Un valor 0 denota que la web de la empresa no dispone de un apartado específico de transparencia donde resida la información requerida.

\section{Estructura: C9}

I 23. La página de inicio contiene un mapa web, sin restricciones de acceso.

I 24. Existe un buscador en un lugar visible y destacado de la web.

Aunque no exista un portal de transparencia, es valorable que la página contenga un mapa web en la portada de inicio, que motive una navegación lógica e intuitiva para facilitar la accesibilidad y la identificación de los contenidos, sin restricciones de acceso.

En todo caso, la localización se ve facilitada si existe un buscador que esté posicionado en un lugar prominente de la página web.

Descripción

Mide si el lugar electrónico donde se encuentra alojada la información está más o menos estructurado, de forma que facilite la identificación y búsqueda de información.

Fórmula de cálculo

Se efectúa una calificación entre 0 y 100 en función de la apreciación sobre la exposición de la información, de forma que permita una búsqueda organizada y fundamentada en la estructura delimitada en la ley.

Definición de los valores

El valor 100 determina que el lugar electrónico que registra los datos sigue una distribución por apartados y subapartados en base a los indicadores de contenido obligatorios. Sucesivamente de mayor a menor ordenación se llegaría al valor 0 , que marca que toda la información de publicidad activa no sigue el estándar que establece la ley de transparencia.

\section{Accesibilidad: C10}

I 25. Web adaptada a colectivos con discapacidad.

Figura dentro, de los principios generales de divulgación en páginas web de la ley de transparencia, por lo que también lo vamos a contemplar.

El Consorcio World Wide Web (W3C) es el organismo que desarrolla estándares de accesibilidad web. Las directrices que redacta tienen tres niveles, nivel A, nivel AA y nivel AAA, que indican el mayor o menor grado de accesibilidad en la web.

La norma de accesibilidad más aceptada en el mundo es la llamada "Web Content Accessibility Guidelines" (WCAG 2.1).

La Directiva sobre accesibilidad web (UE) 2016/2102 establece el 23 de septiembre de 2020 como la fecha en la que todos los sitios web del sector público de la UE deberán ser accesibles para las personas con discapacidad. Tomando como referencia el portal de la administración electrónica ${ }^{10}$ se recoge que la UNEEN 301549:2019 "Requisitos de accesibilidad para productos y servicios TIC" tiene como principal referente las WCAG 2.1 de W3C, siendo una norma que da presunción de conformidad del cumplimiento de los requisitos de la mencionada Directiva.

En la actualización de 2020, las tablas A.1 y A.2 indican los requisitos de accesibilidad de los sitios web y aplicaciones para dispositivos móviles del sector público, siendo la mejora más destacada el nuevo anexo E, en el que se explica el documento y cómo usarlo de forma sencilla. 
Descripción

Para que se encuentre a disposición de las personas con discapacidad, cualquier web debe estar adaptada a estos colectivos, por medios o en formatos adecuados, conforme al principio de accesibilidad universal y diseño para todos.

Fórmula de cálculo

Tomando la referencia de la norma UNE-EN 301549, que no hace distinción de prioridades o niveles, se va a considerar que se cumple o no se cumple con la norma WCAG 2.1, dentro del contexto empresarial.

Definición de los valores

El valor 100 denota que la web es de máxima accesibilidad, cumpliendo la norma y el valor 0 que no se cumple.

\section{2. Índice del Cumplimiento en Publicidad Activa (ICPA)}

El Índice del Cumplimiento en Publicidad Activa (ICPA) es un "indicador" de mínimos que se calcula sobre la información obligatoria de la LTBG y las obligaciones de accesibilidad de las webs.

Este índice está formado por dos componentes:

- Índice del cumplimiento de la información obligatoria (ICIO). Es el índice específico del área 1 relacionado con los contenidos, la forma y la actualización de la publicación y los atributos de la información.

- $\quad$ Índice del cumplimiento del soporte web (ICS).

Como ahora se expondrá, se ha considerado que las ponderaciones de cada uno de los componentes de los índices de evaluación sean proporcionales a los 10 criterios de medición anteriormente definidos en la metodología:

- El índice específico relacionado con la información se pondera por los 7 primeros criterios (3 referidos a la publicación de información y 4 alusivos a los atributos de la información).

Posteriormente se tienen en cuenta y se suma el componente del soporte web, considerando el peso proporcional a los 3 últimos criterios de valoración.

La expresión matemática es la siguiente: ICPA = ICIO x 0,7 + ICS x 0,3.

Se considera que los 10 criterios descritos son todos aplicables a la empresa obligada, y de ahí la ponderación manejada a posteriori sobre los resultados finales, en proporción al número de criterios de cada componente.

El ICPA puede tomar cualquier valor entre 0 y 100 , indicando el porcentaje de cumplimiento de la empresa analizada en materia de publicidad activa que marca la ley de transparencia.

\subsection{1. Índice del Cumplimiento de la Información Obligatoria (ICIO)}

Mide, para la entidad analizada, el grado de cumplimiento en la publicación de sus informaciones obligatorias según la ley de transparencia, en relación con los 7 criterios de medición desarrollados; C1, C2, C3 referentes a la publicación y C4, C5, C6 y C7 relativos a los atributos.

Cabe recordar que cada uno de los 7 criterios tiene la misma importancia, ya que la ley de transparencia no establece ninguna diferencia entre los mismos, pudiendo estar comprendidos entre 0 y 100 puntos, salvo el C3 (Actualización), para el que existía la triple opción de valor 100, valor 50 o valor 0.

El ICIO de un contenido se calcularía como el cociente de la suma de puntuaciones obtenidas en cada una de las informaciones obligatorias en cada criterio, con respecto a la suma total de puntos máximos (700) que puede obtenerse en cada uno de los 7 criterios.

De esta forma, para una información “i” el máximo ICIO $\mathrm{i}=700 / 700=1$.

El ICIO del conjunto de informaciones obligatorias se puede expresar como la media de los grados de cumplimiento de cada información obligatoria. Como identificamos 14 contenidos (I 1 hasta I 14 en la tabla $1)$ :

$\mathrm{ICIO}=$ ICIO $1+$ ICIO $2+\cdots+$ ICIO $14 / 14$

Adicionalmente, se pueden revelar índices de cumplimiento de la información institucional, organizativa y de planificación, que abarca desde el ICIO 1 al ICIO 7, mientras que la información económica, presupuestaria y estadística lo hace desde el ICIO 8 hasta el ICIO 14; lógicamente considerando por separado los 7 primeros contenidos y a continuación los 7 restantes.

El índice del cumplimiento de la información obligatoria también se puede calcular de forma desagregada para cada uno de sus componentes, obteniéndose el grado de cumplimiento de la publicación de la 
información, en función de los criterios C1, C2 y C3 y el grado de cumplimiento de los atributos de la información, teniendo en cuenta los criterios C4, C5, C6 y C7.

De esta forma:

Para una información "i” el máximo ICIO Publicación $=300 / 300=1$

Para una información “i”" el máximo ICIO Atributos $=400 / 400=1$

A partir de aquí se podría llegar al ICIO del total de informaciones obligatorias de publicación de la información:

ICIO Publicación = ICIO Pub $1+$ ICIO Pub $2+\cdots+$ ICIO Pub 14/14

Respecto al ICIO del conjunto de informaciones obligatorias respecto de los atributos:

ICIO Atributos = ICIO Atrib $1+$ ICIO Atrib $2+\cdots+$ ICIO Atrib 14/14

\subsection{2. Índice del Cumplimiento del Soporte Web (ICS)}

Mide el grado de cumplimiento de las obligaciones de transparencia con respecto a la web o soporte electrónico donde se aloja la información. Las condiciones que debe reunir la página web las valoramos con los criterios C8, C9 y C10, teniendo cada uno de ellos la misma importancia, esto es, 100 puntos máximos posibles.

El ICS de un criterio de soporte "s" para cada empresa se calcula como el cociente de la puntuación obtenida en ese criterio y el máximo que puede obtenerse con dicho criterio.

De esta forma, para un criterio "s" el máximo ICS s $=100 / 100=1$.

Finalmente, el ICS se calcula como la media del grado de cumplimiento asociado al soporte web, con respecto al número total de criterios considerados, que son 3:

$\operatorname{ICS}=\operatorname{ICS} 1+\operatorname{ICS} 2+\operatorname{ICS} 3 / 3$

\section{3. Índice de Transparencia y Prevención de la Corrupción (ITPC)}

El Índice de Transparencia y Prevención de la Corrupción (ITPC) se calcula considerando un nivel adicional de transparencia, teniendo presentes los "Principios de Transparencia y Prevención de la Corrupción para las empresas".

Este indicador está formado por dos componentes:

- Índice de cumplimiento en prevención de la corrupción (ICIOP), que está compuesto por el índice de cumplimiento de la información obligatoria, ICIO, específico del área 1, que se va a completar con el índice de cumplimiento de los principios de prevención de la corrupción (ICIP), que es el índice específico del área 2 relacionado con los contenidos, la forma y la actualización de la publicación y los atributos de la información.

- Índice del cumplimiento del soporte web (ICS).

La expresión matemática es la siguiente: ITPC $=($ ICIO + ICIP $) \times 0,7+$ ICS x 0,3.

Teniendo en cuenta que ICIOP = ICIO + ICIP, quedaría como: ITPC $=($ ICIOP $)$ x 0,7 + ICS x 0,3.

Se ha considerado que las ponderaciones de cada uno de los componentes de los índices de evaluación sean proporcionales a los 10 criterios de medición definidos en la metodología.

\section{4. Índice de Transparencia en Publicidad Activa (ITPA)}

El Índice de Transparencia en Publicidad Activa (ITPA) adiciona a los anteriores la información no obligatoria, tanto de carácter financiero como no financiero, en el sentido de mayor desglose de datos o informaciones que sean relevantes para garantizar la transparencia de su actividad.

Este índice está formado por dos componentes:

- Índice de transparencia de la información (ITIPA), que está compuesto por los índices específicos de las áreas 1 y 2 relacionados con los contenidos, la forma y la actualización de la publicación y los atributos de la información, ICIO e ICIP, al que vamos a añadir el índice de la transparencia de la información no obligatoria (ITINO), que es el índice específico del área 3 en este mismo sentido.

- $\quad$ Índice del cumplimiento del soporte web (ICS).

La expresión matemática es la siguiente: ITPA = (ICIO + ICIP + ITINO $)$ x 0,7 + ICS x 0,3.

Teniendo en cuenta que ITIPA = ICIO + ICIP + ITINO, quedaría como: ITPA = (ITIPA) x 0,7 + ICS x 0,3. 
Se ha establecido que las ponderaciones de cada uno de los componentes de los índices de evaluación sean proporcionales a los 10 criterios de medición definidos en la metodología.

\section{Conclusiones}

Los destinatarios de los principios de transparencia y las normas de cumplimiento son el sector público y las entidades privadas. La observancia de la LTBG va a permitir un mejor conocimiento de la información relativa a las ayudas y subvenciones públicas que se hayan recibido, siendo la fuente de obtención de la información es la propia página web de las empresas encuadradas en la categoría de grandes.

En este contexto, ante la cuestión de qué aporta TESUB, los principales argumentos a considerar serían los siguientes:

- Se trata de un modelo específico que permitirá valorar la transparencia en empresas grandes que reciben una cuantía significativa de fondos públicos en el plazo de un año. De forma complementaria, puede hacerse extensivo a otras entidades privadas con pequeños matices.

- Atiende a una finalidad clara en la elaboración de las mediciones, en tres áreas diferenciadas, contribuyendo al conocimiento de varios índices de revelación conexionados con tres de los aspectos o definiciones teóricas de lo que es la transparencia, con un enfoque empresarial pero en un escenario público.

- La contrastación con el sistema español de acreditación de transparencia permite configurar un modelo que posibilite una futura acreditación en transparencia.

- $\quad$ Está diseñado a partir de la Metodología de Evaluación y Seguimiento de la Transparencia de la Actividad Pública (MESTA), que supone un avance respecto de los modelos mayormente centrados en cantidad, pero a la vez superando alguna de sus posibles limitaciones. Se propugna realizar una valoración de cada uno de los indicadores C2 a C7 (publicación y atributos) con relación a cada información o variable de contenido $\mathrm{C} 1$ para evitar sesgos detectados en su aplicación piloto (Ros, 2018).

- Se realiza la contribución de ser una versión definida para empresas grandes, dentro de entidades privadas obligadas a publicidad activa y a facilitar el derecho de acceso por la ley de transparencia. De esta forma contamos con un instrumento de medición tanto cuantitativo como cualitativo, de mayor potencia metodológica sobre los índices de transparencia basados en indicadores dicotómicos que no permiten captar una gradación, con valoraciones que atienden a la calidad de la información y al soporte web.

- Su diseño facilita la comprensión del cumplimiento de las obligaciones legales y su control. El desarrollo expuesto de los criterios de medición aclara cómo realizar las puntuaciones y posibilitará la confección de manera uniforme del Índice del Cumplimiento en Publicidad Activa (ICPA), una vez extendida su aplicación a las diferentes entidades privadas por sectores, proporcionando una visión general de la situación general de la transparencia en publicidad activa en este ámbito.

- Por un lado, evalúa el grado de cumplimiento obligatorio de la ley de transparencia y por otro permite una medición de la eficacia de la transparencia, con indicadores voluntarios añadidos a los obligatorios. Esta definición metodológica inicial de lo que suponen las informaciones no obligatorias se diferencian de los elementos de la publicidad activa del área 1 y de su complemento del área 2, de medidas más específicas contra la corrupción, que hemos adicionado a MESTA. Sin embargo, pueden desarrollarse posteriormente de forma más específica para el tipo de empresa y entidad privada e ir variando en el tiempo, ya que el propio concepto es dinámico y cambiante.

De forma más amplia, pasamos a destacar algunos aspectos relacionados con los puntos anteriores.

Partiendo de la premisa contrastada que en la medición de la transparencia no existen estándares únicos, la propuesta de 25 indicadores elaborada en la tabla 1 se articula en torno a un área de transparencia relacionada con información obligatoria a publicar, en base a la LTBG:

- Sintetiza adecuadamente las obligaciones legales, para contribuir a la elaboración de un índice de transparencia, en este caso de cumplimiento.

Se valora además de la propia emisión de información, otras características y los principios relacionados con la forma de realizar la publicación, que las entidades privadas receptoras de subvenciones oficiales, obligadas a publicidad activa, tienen que divulgar.

Se conexiona con un total de 19 indicadores del sistema español de acreditación de la transparencia para las entidades privadas de mercado en las áreas de publicidad activa (13 indicadores), y organización transparente (6 indicadores), que se ligan con los principios generales de divulgación en páginas web. 
Las áreas de transparencia 2 y 3 igualmente se han contrastado con los indicadores del sistema español de acreditación de la transparencia, para configurar un modelo que sirva a este tipo de empresas que reciben subvenciones, para poder acreditarse en transparencia y de esta forma evitar dobles esfuerzos en la configuración de los requisitos precisos. Si bien MESTA es aplicable a las páginas web de los organismos integrantes del sector público estatal y al resto de sujetos obligados por el artículo 2 de la ley de transparencia, se ha tomado como un modelo de referencia para diseñar TESUB, como modelo propio para las entidades privadas, citadas en el artículo 3 de la ley.

TESUB posibilita la valoración de la transparencia de la web corporativa y de la información suministrada en sentido amplio, ya que cada uno de los tres índices aporta una medición específica, que a su vez se pueden ir agregando:

- $\quad$ El Índice de Cumplimiento en Publicidad Activa (ICPA) es un indicador de mínimos, que se calcula sobre la información obligatoria de la ley de transparencia, aspectos cualitativos relacionados con la calidad y presentación de la información, y las obligaciones de accesibilidad de las webs. Permite conocer el grado de cumplimiento en el que se encuentra una empresa y comparar el nivel de transparencia en publicidad activa entre sujetos obligados.

- $\quad$ El Índice de Transparencia y Prevención de la Corrupción (ITPC) nos permite homogeneizar esta área del modelo para empresas grandes cotizadas y no cotizadas, pues "alguno" de los criterios de contenido son obligatorios en sociedades cotizadas y voluntarios en no cotizadas.

El Índice de Transparencia en Publicidad Activa (ITPA) aglutina a la información obligatoria y los principios generales de divulgación en páginas web, la valoración de la transparencia en relación con la corrupción y la información no obligatoria. Queda pendiente la posibilidad de un mayor desarrollo y concreción en el modelo TESUB del área ligada con información voluntaria publicada, que desarrolla principalmente las tres dimensiones de la RSC.

En general, la información que nos proporcionarán los sucesivos índices de nuestro modelo, desagregada por componentes de la publicidad activa y por áreas de transparencia, nos permitirá identificar una potencial mejora para cada uno de ellos y avanzar en la transparencia pública de las empresas que reciben subvenciones.

\section{Referencias bibliográficas}

Agencia Estatal de Evaluación de las Políticas Públicas y la Calidad de los Servicios, (AEVAL) (2016) Informe "Metodología de evaluación y seguimiento de la transparencia" y sus Anexos. Disponible: https://www.consejodetransparencia.es/ct_Home/Actividad/documentacion.html (acceso 5 de abril de 2020).

Alonso, $\mathrm{M}^{\mathrm{a}}$ del M. (2009) La transparencia de las empresas en internet para la confianza de los accionistas e inversores: Un análisis empírico. Cuadernos de Administración, 22 (38). Disponible: https://revistas.javeriana.edu.co/index.php/cuadernos_admon/article/view/3860.

Amoedo, J. D. (2016) Consecuencias legales y económicas de la Ley de Transparencia 19/2013 para empresas privadas. Revista Internacional de Transparencia e Integridad, $\mathrm{N}^{\circ} 1, \quad \mathrm{pp} .1-13 . \quad$ Disponible: http://revistainternacionaltransparencia.org/numero-i.

Andrade, J. A., \& Yaskelly, Y. (2007) Sistemas transparentes para gobiernos electrónicos eficientes. Enl@ce: Revista Venezolana de Información, Tecnología y Conocimiento, 4 (2), pp. 81-95.

Angla, J., Rodríguez, M., Vidal, M., \& Travé Bautista, M. (2002) La información consolidada divulgada por los grupos de sociedades que cotizan en las bolsas de valores españolas: Factores explicativos. Comunicación presentada en $X$ Congreso ASEPUC.

Archel, P. (2001) Algunos determinantes de la información medioambiental divulgada por las empresas españolas cotizadas. Revista de Contabilidad-Spanish Accounting Review, 4 (7), pp. 129-153.

Arellano Gault, D. (2007) Fallas de transparencia: Hacia una incorporación efectiva de políticas de transparencia en las organizaciones públicas. Convergencia, 14 (45), pp. 31-46. Disponible: http://www.scielo.org.mx/scielo.php?script=sci arttext\&pid=S1405-14352007000300002\&lng=es\&tlng=es.

Argandoña, A. (2003) Private-to-private corruption. Journal of Business Ethics, 47 (3), pp. 253-267. DOI:10.1023/A:10262662219609.

Arizmendi, M. E. (2017) Metodología de evaluación y seguimiento de la transparencia de la actividad pública (MESTA). Revista Española de la Transparencia, № 4, pp. 40-44. Disponible: www.revistatransparencia.com.

Armstrong, E. (2005) Integrity, transparency and accountability in public administration: Recent trends, regional and international developments and emerging issues. United Nations, Department of Economic and Social Affairs, pp. 110.

Armstrong, C. L. (2011) Providing a clearer view: An examination of transparency on local government websites. Government Information Quarterly, 28 (1), pp. 11-16. DOI:10.1016/j.giq.2010.07.006.

Asociación Española de Acreditación de la Transparencia, (ACREDITRA) (2016) Sistema español de acreditación de la transparencia (SIESTRA 2016). Disponible: www.acreditra.com/los-indicadores/ (acceso 20 de marzo de 2019). 
Ayestarán, S. (2016) ¿Cómo podemos mejorar la transparencia en las organizaciones? Revista Internacional de Transparencia e Integridad, № 1, pp. 1-10. Disponible: http://revistainternacionaltransparencia.org/numero-i.

Baraibar-Diez, E., \& Luna-Sotorrío, L. (2012) Transparencia social e hipótesis del impacto social. Análisis en el IBEX35. Universia Business Review, $\mathrm{N}^{\mathrm{O}} 36, \quad$ pp. 108-123. Disponible: https://www.redalyc.org/articulo.oa?id=43324833003.

Bastida, A. F., \& Benito, B. (2006) Propuesta de un índice de transparencia presupuestaria. IX Jornada de Contabilidad Pública ASEPUC, Logroño, La Rioja (España). Disponible: http://hdl.handle.net/10317/1039.

Bauhr, M., \& Grimes, M. (2014). Indignation or resignation: The implications of transparency for societal accountability. Governance, 27 (2), pp. 291-320. DOI:10.1111/gove.12033.

Bovens, M. (2007) Analysing and assessing accountability: A conceptual framework 1. European Law Journal, 13 (4), pp. 447-468.

Bravo, R., Matute, J., \& Pina, J. M. (2011) Efectos de la imagen corporativa en el comportamiento del consumidor. Un estudio aplicado a la banca comercial. INNOVAR. Revista de Ciencias Administrativas y Sociales, 21 (40), pp. 3551. Disponible: https://www.redalyc.org/articulo.oa?id=81822453004.

Bushman, R. M., \& Smith, A. J. (2003) Transparency, financial accounting information, and corporate governance. Economic Policy Review, 9 (1), pp. 65-87. Disponible: https://ssrn.com/abstract=795547.

Buzby, S. L. (1975) Company size, listed versus unlisted stocks, and the extent of financial disclosure. Journal of Accounting Research, 13 (1), pp. 16-37. DOI: 10.2307/2490647.

Carmona, S. N., \& Carrasco, F. (1988) Información de contenido social y estados contables: Una aproximación empírica y algunas consideraciones teóricas. Actualidad Financiera, No 41, pp. 2175-2192.

Carrol, A. (1979) A three-dimensional conceptual model of corporate performance. The Academy of Management Review, 4 (4), 497. DOI:10.2307/257850.

Chow, C. W., \& Wong-Boren, A. (1987) Voluntary financial disclosure by Mexican corporations. Accounting Review, 62 (3), pp. 533-541. Disponible: http://www.jstor.org/stable/247575.

Cooke, T. E. (1989) Disclosure in the corporate annual reports of Swedish companies. Accounting and Business Research, 19 (74), pp. 113-124. DOI: 10.1080/00014788.1989.9728841.

Del Campo, C., Hermosa del Vasto, P., Urquía-Grande, E., \& Jorge, S. (2020) Country performance in the South American region: A multivariate analysis. International Journal of Public Administration, pp. 1-19. DOI:10.1080/01900692.2020.1728314.

Delgado, F., López, F. J., \& Sierra, J. (2015) Regulación y sistemas de evaluación de la transparencia en España. Revista de Derecho de la Hacienda Pública, № 5, pp. 111-134.

Espinosa, M., Sabater, A. M. (2002) Determinantes de calidad en la información voluntaria para empresas del mercado continuo español. Un análisis empírico. Comunicación presentada en X Congreso ASEPUC.

Ettredge, M., Richardson, V. J., \& Scholz, S. (2002) Dissemination of information for investors at corporate web sites. Journal of Accounting and Public Policy, 21 (4-5), pp. 357-369. DOI:10.1016/S0278-4254(02)00066-2.

Etzioni, A. (2014) The limits of transparency. Public Administration Review, 74 (6), pp. 687-688. DOI:10.1111/puar.12276.

Filgueiras, F. (2016) Transparency and accountability: Principles and rules for the construction of publicity. Journal of Public Affairs, 16 (2), pp. 192-202. DOI:10.1002/pa.v16.2.

Firth, M. (1980) Takeovers, shareholder returns, and the theory of the firm. The Quarterly Journal of Economics, 94 (2), pp. 235-260. DOI:10.2307/1884539.

Gandía, J. L. (2002) La divulgación de información sobre intangibles en internet: Evidencia internacional. Revista Española de Financiación y Contabilidad, 31 (113), pp. 767-802.

García Melián, J. C. (2016) Control de la transparencia. baremos y acreditación. Manuel Sánchez De Diego (Coord.), 31 visiones de la transparencia en España. Madrid: UCM, pp. 324-340.

García Meca, E., \& Martínez, I. (2004) Divulgación voluntaria de información empresarial: Índices de revelación. Partida Doble, № 157, pp. 66-77.

García Benau, Ma . A., \& Monterrey, J. (1993) La revelación voluntaria en las compañías españolas cotizadas en bolsa. Revista Española de Financiación y Contabilidad, 23 (74), pp. 53-70.

Giner, B. (1997) The influence of company characteristics and accounting regulation on information disclosed by Spanish firms. European Accounting Review, 6 (1), pp. 45-68. DOI:10.1080/096381897336863.

Grant, R. W., \& Keohane, R. O. (2005) Accountability and abuses of power in world politics. American Political Science Review, 99 (1), pp. 29-43. DOI:10.1017/S0003055405051476.

Gray, R., Kouhy, R., \& Lavers, S. (1995) Constructing a research database of social and environmental reporting by UK companies. Accounting, Auditing \& Accountability Journal, 8 (2), pp. 78-101. DOI:10.1108/09513579510086812.

Guthrie, J., Ball, A., \& Farneti, F. (2010) Advancing sustainable management of public and not for profit organizations. Public Management Review, 12 (4), pp. 449-459. DOI:10.1080/14719037.2010.496254.

Hermosa del Vasto, P., del Campo, C., Urquía-Grande, E., \& Jorge, S. (2019) Designing an accountability index: A case study of South America Central governments. Central European Journal of Public Policy, 13 (2), pp. 1-14. DOI:10.2478/cejpp-2019-0009.

Lang, M., \& Lundholm, R. (1993) Cross-sectional determinants of analyst ratings of corporate disclosures. Journal of Accounting Research, 31 (2), pp. 246-271. DOI:10.2307/2491273. 
Larrán J. M., \& Giner, B. (2001) La oferta de información financiera en internet: Un estudio de las grandes compañías españolas. Comunicación presentada en XI Congreso de AECA.

Longinos, J., Arcas, N., Martínez, I. M., Olmedo, I (2012) Transparencia, gobierno corporativo y participación: Claves para la implantación de un código de conducta en empresas de economía social. REVESCO. Revista de Estudios Cooperativos, Segundo Cuatrimestre, No 108, pp. 86-112. DOI:10.5209/rev_REVE.2012.v18.39588.

Lourenço, R. P. (2015) An analysis of open government portals: A perspective of transparency for accountability. Government Information Quarterly, 32 (3), pp. 323-332. DOI:10.106/j.giq.2015.05.006.

Marcuello, C., Bellostas, A., \& Moneva, J. M. (2007) Transparencia y rendición de cuentas en las empresas de inserción. CIRIEC-España, Revista de Economía Pública, Social y Cooperativa, № 59, pp. 91-122. Disponible: https://www.redalyc.org/articulo.oa?id=17405905.

Medina, J. M., Lavín, J., Mora, A., \& de-la-Garza, I. (2011) Influence of information technology management on the organizational performance of the small and medium-sized enterprises. Innovar. Revista de Ciencias

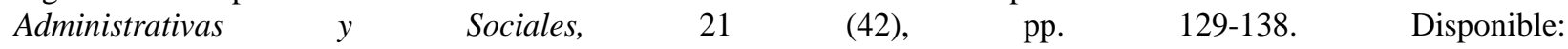
https://revistas.unal.edu.co/index.php/innovar/article/view/35461.

Meijer, A. (2013) Understanding the complex dynamics of transparency. Public Administration Review, 73 (3), pp. 429 439. DOI:10.1111/puar.2013.73.issue-3.

Molina, P., Simelio, N., \& Corcoy, M. (2017) Metodologías de evaluación de la transparencia: Procedimientos y problemas. Revista Latina de Comunicación Social, No 72, pp. 818-831. DOI:10.4185/RLCS-2017-1194.

Ortiz, E., \& Clavel, J. G. (2006) Índices de revelación de información: Una propuesta de mejora de la metodología. Aplicación a la información sobre recursos humanos incluida en los informes 20F. Revista Española de Financiación y Contabilidad, 35 (128), pp. 87-113.

Parris, D. L., Dapko, J. L., Arnold, R. W., \& Arnold, D. (2016) Exploring transparency: a new framework for responsible business management. Management Decision, 54 (1), pp. 222-247. DOI:10.1108/md-07-2015-0279.

Piotrowski, S. J. (2009) Is transparency sustainable? Public Administration Review, 69 (2), pp. 359-361. DOI:10.1111/puar.2009.69.issue-2.

Plá, O. (1997) La transparencia de información como base del contrato federal: Una propuesta para México. Perfiles Latinoamericanos: Revista de la Facultad Latinoamericana de Ciencias Sociales, Sede México, 6 (10), pp. $125-138$. Disponible: http://www.redalyc.org/articulo.oa?id=11501006.

Propper, C., \& Wilson, D. (2003) The use and usefulness of performance measures in the public sector. Oxford Review of Economic Policy, 19 (2), pp. 250-267. DOI:10.1093/oxrep/19.2.250.

Ros, J. L. (2018) La evaluación de la transparencia en España a debate metodológico: MESTA e Índices de Transparencia Internacional. Revista Internacional de Transparencia e Integridad, N$^{\circ}$ 6, pp. 1-22. Disponible: http://revistainternacionaltransparencia.org.

Ruiz, M., Tirado, P., \& Morales, A. C. (2008) Transparencia y calidad de la información económico-financiera en las entidades no lucrativas. Un estudio empírico a nivel andaluz. CIRIEC-España, Revista de Economía Pública, Social y Cooperativa, No 63, pp. 253-274. Disponible: http://www.redalyc.org/articulo.oa?id=17412307010.

Sierra, M., \& Rojo, A. (2002) La revelación de información sobre activos intangibles en la gran empresa español: Un estudio empírico. Comunicación presentada en X Congreso ASEPUC.

Sierra, J. (2014) Certificación en transparencia: El sistema español de acreditación de la trasparencia. Revista Más Poder Local, No 21, pp. 28-32. Disponible: https://maspoderlocal.es/ediciones.

Sierra, J. (2018) Mediciones y premios de transparencia. Revista Española de la Transparencia, No 7, pp. 71-97. Disponible: www.revistatransparencia.com.

Street, D. L., \& Bryant, S. M. (2000) Disclosure level and compliance with IASs: A comparison of companies with and without US listings and filings. The International Journal of Accounting, 35 (3), pp. 305-329.

Transparency International España, (TI-España). (2012) Principios de Transparencia para Empresas. Disponible: https://transparencia.org.es/principios-de-transparencia-para-empresas/ (acceso 11 de noviembre de 2019).

Transparency International. (2017) Corruption perceptions index $2017 . \quad$ Disponible: https://www.transparency.org/en/cpi/2017.

Uvalle, R. (2008) Gobernabilidad, transparencia y reconstrucción del Estado. Revista mexicana de ciencias políticas y sociales, 50 (203), pp. 97-116. DOI: 10.22201/fcpys.2448492xe.2008.203.41995.

Vanstraelen, A., Zarzeski, M. T., \& Robb, S. W. (2003) Corporate nonfinancial disclosure practices and financial analyst forecast ability across three European countries. Journal of International Financial Management \& Accounting, 14 (3), pp. 249-278. DOI:10.1111/1467-646X.00098.

Wallace, R. O., Naser, K., \& Mora, A. (1994) The relationship between the comprehensiveness of corporate annual reports and firm characteristics in Spain. Accounting and Business Research, 25 (97), pp. 41-53. DOI:10.1080/00014788.1994.9729927. 